\title{
Tribenzacepentalene Dianion and 4,7-Disubstituted Tribenzodihydroacepentalene Derivatives: Formation, Reactions, and Structural Properties of Potential Tribenzacepentalene Precursors
}

\author{
Rainer Haag, ${ }^{\dagger}$ Björk Ohlhorst, ${ }^{\dagger}$ Matthias Noltemeyer, ${ }^{\dagger, \ddagger}$ Roland Fleischer, ${ }^{\dagger, \neq}$ \\ Dietmar Stalke, ${ }^{\dagger, \ddagger}$ Andreas Schuster, ${ }^{\S}$ Dietmar Kuck, ${ }^{*, 8}$ and Armin de Meijere ${ }^{*, \dagger}$
}

Contribution from the Institut für Organische Chemie der Georg-August-Universität Göttingen, Tammannstrasse 2, D-37077 Göttingen, Germany, and Fakultät für Chemie der Universität Bielefeld, Universitätsstrasse 25, D-33615 Bielefeld, Germany

Received July 3, $1995^{\otimes}$

\begin{abstract}
Upon treatment of tribenzotriquinacene (4a) $(\mathrm{R}=\mathrm{H})$ and its centro-alkyl-substituted derivatives $\mathbf{4 b}-\mathbf{d}$ ( $\mathrm{R}=\mathrm{CH}_{3}, \mathrm{C}_{2} \mathrm{H}_{5}, \mathrm{CH}_{2} \mathrm{Ph}$ ) with the strongly basic mixture of $n$-BuLi and KO'Pen, 2 -fold deprotonation combined with (formal) elimination of $\mathrm{RH}$ from positions $\mathrm{C}(1)-\mathrm{C}(10)$ occurs to generate tribenzacepentalene dianion $\mathbf{5}-\mathbf{K}_{2}$ with varying ease. Dianion $\mathbf{5 - \mathbf { K } _ { 2 }}$ can be trapped with various electrophiles to give 4,7-disubstituted tribenzodihydroacepentalenes $\mathbf{6 c}-\mathbf{f}$ in good yields. Compounds $6 \mathbf{a}-\mathbf{f}$ contain an extremely out-of-plane bent $\mathrm{C}(1)=\mathrm{C}(10)$ double bond, as shown by X-ray structure analyses of $6 \mathbf{b}-\mathbf{d}$, and therefore possess an increased reactivity. 4,7Dihydrotribenzacepentalene (6a) obtained upon protonation of 5 at $-78{ }^{\circ} \mathrm{C}$ dimerizes at higher temperatures ( $\geq 0$ ${ }^{\circ} \mathrm{C}$ ) toward the head-to-head [ $\left.2+2\right]$ dimer 22 . At elevated temperatures $\left(\geq 220^{\circ} \mathrm{C}\right), 22$ is cleaved to regenerate $6 \mathrm{a}$ which can be trapped with anthracene and tetracyclone to give the highly condensed Diels-Alder adducts 23 and 24. Likewise, 6 a generated from 5 at low temperatures can be trapped with 1,3-diphenylisobenzofuran, yielding 25. $\mathrm{X}$-ray structure analyses of dimer 22 and adduct 23 revealed strongly elongated 1,1,2,2-tetraarylethane $\mathrm{C}-\mathrm{C}$ bonds, which are attributed to through-bond $\pi-\sigma^{*}$ couplings in these rigid frameworks. The 4,7-bis(trimethylstannyl)tribenzodihydroacepentalene (6f) undergoes clean transmetalation with methyllithium to give pure dilithium tribenzacepentalenediide (5- $\mathbf{L i}_{2}$.) Crystal structure analysis reveals that the dianionic fragments $\mathbf{5 - \mathbf { L i } _ { 2 }}$ in these solventseparated ion pairs are considerably curved.
\end{abstract}

\section{Introduction}

Triquinacene (1), ${ }^{\text {la-e }}$ first synthesized in 1964 by R. B. Woodward et al., has since been envisaged as the logical precursor $^{1 \mathrm{a}, \mathrm{f}}$ to the yet elusive acepentalene (cyclopenta[ $[c d]$ pentalene, 3 ). The fully unsaturated hydrocarbon $\mathbf{3}$, which is the smallest curved subunit of the highly strained $\mathrm{C}_{20}$ fullerene ${ }^{2}$ comprises a $\pi$-electron system of long-standing theoretical interest. $^{3}$ According to Hückel MO theory, acepentalene has a triplet ground state. ${ }^{3 a}$ However, even if the degeneracy of the

\footnotetext{
* To whom correspondence should be addressed.

${ }^{*}$ Georg-August-Universität Göttingen.

₹ Performed the crystal structure analyses.

Universität Bielefeld.

\& Abstract published in Advance ACS Abstracts, October 1, 1995.

(1) (a) Woodward, R. B.; Fukunaga, T.; Kelly, R. C. J. Am. Chem. Soc. 1964, 86, 3162-3165. (b) Jacobsen, I. T. Acta Chem. Scand. 1967, 21, 2235-2246. (c) Wyvratt, M. J.; Paquette, L. A. Tetrahedron Lett. 1974, 2433-2436. (d) Deslongchamps, P.; Cheriyan, U. O.; Lambert, Y.; Mercier, J. C.; Ruest, L.; Russo, R.; Soucy, P. Can. J. Chem. 1978, 56, 1687-1704 (e) Gupta, A. K.; Lannoye, G. S.; Kubiak, G.; Schkeryantz, J.; Wehrli, S.; Cook, J. M. J. Am. Chem. Soc. 1989, 111, 2169-2179. (f) Butenschön, H. de Meijere, A. Tetrahedron 1986, 42, 1721-1729.

(2) (a) Wahl, F.: Wörth, J.; Prinzbach, H. Angew. Chem. 1993, 104 1788-1791; Angew. Chem., Int. Ed. Engl. 1993, 32, 1722-1726. (b) Prinzbach, H.; Weber, K. Angew. Chem. 1994, 105, 2329-2348; Angew. Chem., Int. Ed. Engl. 1994, 33, 2239-2258 and literature cited therein.

(3) (a) Streitwieser, A., Jr. Molecular Orbital Theory for Organic Chemists; Wiley: New York, 1961. (b) Zahradnik, R.; Michel, J.; Koutecky, J. Collect. Czech. Chem. Commun. 1964, 29, 1932-1944. (c) Zahradnik, R.; Michel, J. Collect. Czech. Chem. Commun. 1965, 30, 3529-3536. (d) Hess, B. A., Jr.; Schaad, L. J. J. Org. Chem. 1971, 36, 3418-3423, (e) Gutman, I.; Trinajstic, N. Croat. Chem. Acta 1975, 47, 35-39. (f) Thomas, F.; Fernandez-Alonso, J. I. An. Quim. 1976, 122-123. (g) Gutman, I.; Milun, M.; Trinajstic, N. J. Am. Chem. Soc. 1977, 99, 1692-1704. (h) Koutecky, V. B.; Koutecky, J.; Michel, J. Angew. Chem. 1987, 99, 216-236; Angew. Chem., Int. Ed. Engl. 1987, 26, 170-190.
}

two highest MO's were lifted due to Jahn-Teller distortion, the strain in the molecule should be prohibitively large, so that 3 would not be isolable at ambient temperature. ${ }^{4}$ By contrast, the dianion of acepentalene $(2)^{5}$ is a closed-shell system ${ }^{4}$ and thereby electronically more favorable than the uncharged compound 3. In addition, it should be less strained than 3 owing to its delocalized charges. ${ }^{6}$

Since the time when Woodward synthesized triquinacene (1), Lochmann discovered and Schlosser popularized as well as further developed the strongly basic mixtures of an alkyllithium and a potassium alkoxide, hence called the LochmannSchlosser bases. ${ }^{7}$ The most frequently used "base cocktail", a mixture of $n$-butyllithium and potassium tert-pentoxide, effects deprotonation even of unactivated allylic $\mathrm{C}-\mathrm{H}$ bonds like those in triquinacene (1). The active species in such deprotonations is an aggregated form of $n$-butylpotassium, ${ }^{8}$ which is definitely more basic than $n$-butyllithium. ${ }^{9}$ It is also known that hydride elimination can occur from these metalated species at elevated

\footnotetext{
(4) Butenschön, H.; de Meijere, A. Helv. Chim. Acta 1985, 68, 16581669.

(5) We recognize that the correct nomenclature of dianions $2-\mathbf{K}_{2}$ and $\mathbf{5}-\mathbf{K}_{\mathbf{2}}$ is dipotassium acepentalenediide and dipotassium tribenzacepentalenediide, respectively. This can easily be seen from Scheme 1. Ions 2 and 5 are 2-fold negatively charged molecules of acepentalene (3) and tribenzacepentalene (7), respectively. Formally, 2 and 5 can be transformed into 3 and 7 by 2 -fold oxidation. In contrast to previous papers ${ }^{12,13,20,31}$ we no longer use the term "dihydrodianions", which is also correct but misleading.

(6) (a) Gobbi, A.; Mac Dougall, P. J.; Frenking, G. Angew. Chem. 1991, 103, 1038-1040; Angew. Chem., Int. Ed. Engl. 1991, 30, 1001-1003. (b) Klein, J. Tetrahedron 1988, 44, 503-518 and literature cited therein.

(7) (a) Lochmann, L.; Pospisil, J.; Lim, D. Tetrahedron Lett. 1966, 257260. (b) Schlosser, M.; Strunk, S. Tetrahedron Lett. 1984, 741-744. (c) Schlosser, M. Pure Appl. Chem. 1988, 60, 1627-1634.
} 
Scheme 1
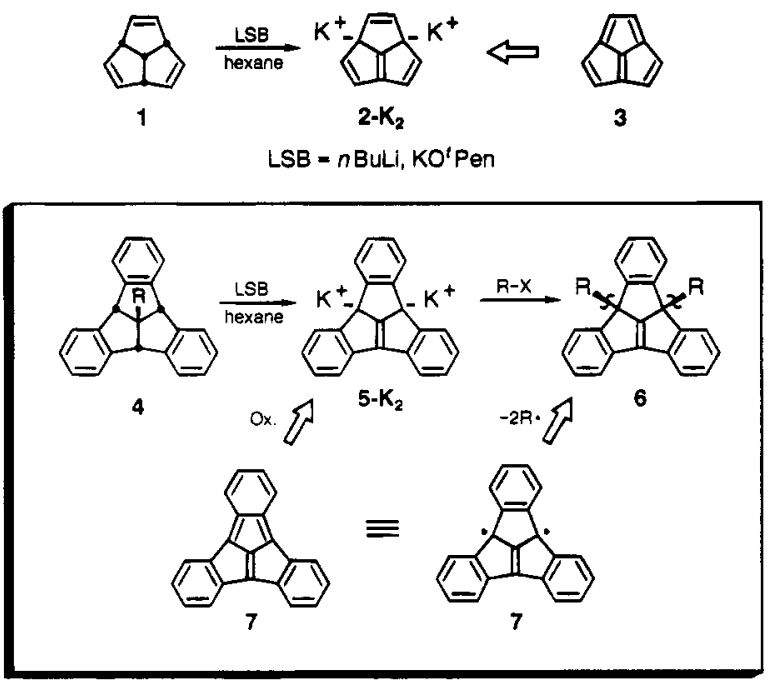

temperature $\left(70{ }^{\circ} \mathrm{C}\right)$, as reported by Schleyer et al., ${ }^{10}$ with alkoxides acting as catalysts. ${ }^{11}$ Treatment of triquinacene (1) with Lochmann-Schlosser base (LSB) therefore easily generates the acepentalene dianion 2-K $\mathbf{K}_{2}$ in a one-pot reaction, as reported previously. ${ }^{12}$

The fact that the corresponding tribenzotriquinacene (4a) $(\mathbf{R}$ $=\mathrm{H})^{13-15}$ is more readily and efficiently transformed into the corresponding fully unsaturated salt, dipotassium tribenzacepentalenediide $\left(5-K_{2}\right),{ }^{5}$ than the parent triquinacene (1) is in line with the common stabilization of conjugated nonaromatic hydrocarbons and their ions by benzoannelation. ${ }^{16}$ Therefore, tribenzacepentalene (7) should offer a much better chance for being isolated than acepentalene (3). In principle, the synthesis of tribenzacepentalene (7) can be achieved along two different routes starting from the tribenzacepentalene dianion (5) (Scheme $1)$. One would be by formation of an appropriately 4,7disubstituted tribenzodihydroacepentalene 6 and subsequent homolytic removal of the two substituents; the second possibility would be the direct oxidation of the dianion $\mathbf{5}$. The homolytic removal of the two substituents in $\mathbf{6}$ appears quite promising, especially for derivatives with weak carbon-substituent bonds.

The acidity of the benzhydrylic bridgehead hydrogens in $\mathbf{4 a}$ is higher compared to that of the allylic positions in $1,{ }^{17}$ which also holds for several centro-alkyl-substituted tribenzotriquinacenes ${ }^{14,18}$ such as the readily accessible centro-methyl derivative $4 b(R=M e)$. This fact has opened a convenient preparative route to tribenzacepentalene dianion (5) and to 4,7tribenzodihydroacepentalene derivatives $\mathbf{6}$, as well as to novel,

(8) (a) Lochmann, L.; Bauer, W. J. Am. Chem. Soc. 1992, 114, 74827489. (b) Harder, S.; Streiwieser, A. Angew. Chem. 1993, 105, 1108-1110, Angew. Chem., Int. Ed. Engl. 1993, 32, 1066-1068.

(9) Brandsma, L. Preparative Organometallic Chemistry; Springer: New York, 1990; Vol. 2, pp 15-23.

(10) (a) Clark, T.; Schleyer, P. v. R. J. Chem. Soc., Chem. Commun. 1976, 798-799. (b) Wilhelm, D.; Clark, T.; Friedel, T.; Schleyer, P. v. R. Chem. Ber. 1983, 116, 751-760.

(11) Glaze, W. H.; Adams, G. M. J. Am. Chem. Soc. 1966, 88, 46534656.

(12) Lendvai, T.; Friedel, T.; Butenschön, H.; Clark, T.; de Meijere, A Angew. Chem. 1986, 98, 734-735; Angew. Chem., Int. Ed. Engl. 1986 $25,719-720$.

(13) Kuck, D.: Schuster, A.; Ohlhorst, B.; Sinnwell, V.; de Meijere, A. Angew. Chem. 1989, 101, 626-628; Angew. Chem., Int. Ed. Engl. 1989, $28,595-597$ 1460.

(14) Kuck, D.; Lindenthal, T.; Schuster, A. Chem. Ber. 1992, 125, 1449-

(15) Kuck, D.; Neumann, E.; Schuster, A. Chem. Ber. 1994, 127, 151164

(16) Bausch, W. J.; Gregory, P. S.; Olah, G. A.; Prakash, G. K. S Schleyer, P. v. R.; Segal, G. A. J. Am. Chem. Soc. 1989, 111, 3633-3640.
Scheme 2

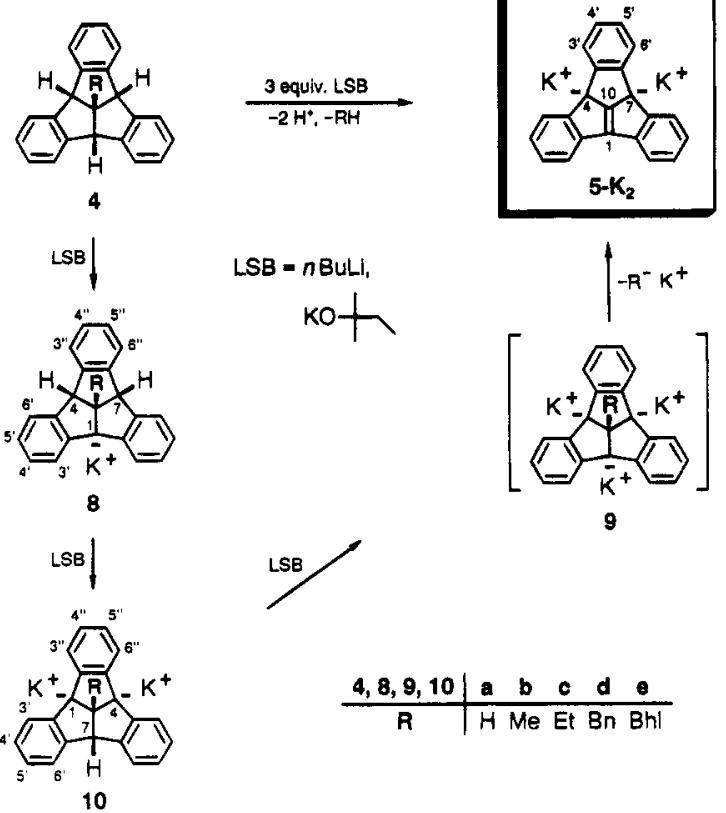

highly complex polycyclic hydrocarbons containing the tribenzotriquinacene (or trifuso-centrotriindan ${ }^{19}$ ) unit.

In this paper we present a full report on the formation, the chemistry, and the structure of tribenzacepentalene dianion (5) as well as the synthesis, structural details, and reactions of 4,7tribenzodihydroacepentalene derivatives $6 \mathbf{a}-\mathbf{f}$.

\section{Results and Discussion}

Formation of Dipotassium Tribenzacepentalenediide (5$\mathbf{K}_{2}$ ). Tribenzotriquinacene $(\mathbf{4 a})$ is easily transformed into dipotassium tribenzacepentalenediide $\left(\mathbf{5}-\mathbf{K}_{2}\right)^{5}$ in a one-pot reaction with Lochmann-Schlosser base (LSB) in high yield. ${ }^{13}$ The interesting mechanism of this reaction was studied in detail since dianion $\mathbf{5}-\mathbf{K}_{\mathbf{2}}$ is not a simple deprotonation product of $\mathbf{4 a}$. In formal terms, $\mathbf{5}-\mathbf{K}_{\mathbf{2}}$ is generated from $\mathbf{4} \mathbf{a}$ by 2 -fold deprotonation and subsequent oxidation (i.e., elimination of hydrogen). As reported recently, even the centro-substituted tribenzotriquinacenes $\mathbf{4} \mathbf{b}-\mathbf{d}$ undergo this deprotonation-elimination reaction. ${ }^{20}$ Again formally, a very unusual elimination of an alkane occurs in these cases. There are only very few precedents ${ }^{21}$ for this kind of elimination reaction, and none of them have been used for preparative purposes.

In order to elucidate the mechanism of the formation of tribenzacepentalene dianion $\mathbf{5}-\mathbf{K}_{\mathbf{2}}$, the easily available centrosubstituted tribenzotriquinacenes $4 \mathbf{b}-\mathbf{e}^{14}$ were treated with 3 equiv of LSB under identical conditions (hexane, $24 \mathrm{~h}$ at 22 ${ }^{\circ} \mathrm{C}, 48 \mathrm{~h}$ at $69^{\circ} \mathrm{C}$ ) to give mixtures of potassium salts, which were analyzed by NMR spectroscopy. The unsubstituted compound $4 a(R=H)$ was reacted under the same conditions as a reference. Varying amounts of monopotassium salts $8 \mathbf{a}-\mathbf{e}$ and dipotassium salts $10 \mathbf{b}-\mathbf{d}$, as the products of single and double deprotonation of the precursor tribenzotriquinacenes 4a-e, were observed (Scheme 2). Most intriguing, however, was the presence of the unsaturated dianion $\mathbf{5}-\mathbf{K}_{\mathbf{2}}$ in each of the product mixtures (Table 1 ).

The relative leaving tendencies of the expelled anions as $\mathrm{R}^{-} \mathrm{K}^{+}$correlate with the relative stabilities of the expelled

(17) The increased acidity of $4 a$ as compared to 1 is also reflected from gas-phase deprotonation by $\mathrm{F}^{-}$and $\mathrm{OH}^{-}$ions, as studied by negative chemical ionization mass spectrometry (ref 13). See also: (b) Harrison, A G. Chemical Ionization Mass Spectrometry; CRC Press: Boca Raton, FL, 1992; pp 90-112.

(18) Kuck, D. Angew. Chem. 1984, 96, 515-516; Angew. Chem., Int. Ed. Engl. 1984, 23, 508-509. 

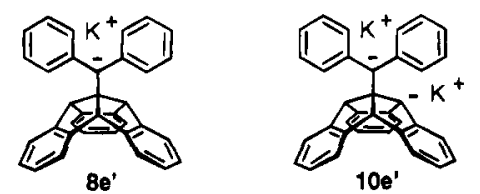

Figure 1. Competing monoanion $8 \mathrm{e}^{\prime}$ and dianion $10 \mathrm{e}^{\prime}$.

Table 1. Relative Abundances of Anions 8, 10, and 5-K Formed from Tribenzotriquinacenes $4 a-e$ with 3 equiv of LochmannSchlosser Base, As Determined by ${ }^{1} \mathrm{H}$ NMR Spectroscopy

\begin{tabular}{clccc}
\hline substrate & substituent $\mathrm{R}$ & monoanion 8 & dianion 10 & dianion 5-K \\
\hline $\mathbf{4 a}$ & $\mathrm{H}$ & 0.4 & & 1.0 \\
$\mathbf{4 b}$ & $\mathrm{CH}_{3}$ & 2.7 & 2.3 & 1.0 \\
$\mathbf{4 c}$ & $\mathrm{C}_{2} \mathrm{H}_{5}$ & 9.3 & 7.2 & 1.0 \\
$\mathbf{4 d}$ & $\mathrm{CH}_{2} \mathrm{C}_{6} \mathrm{H}_{5}$ & 1.1 & 1.0 & 1.0 \\
$\mathbf{4 e}$ & $\mathrm{CH}_{2}\left(\mathrm{C}_{6} \mathrm{H}_{5}\right)_{2}$ & 5.0 & & 1.0 \\
\hline
\end{tabular}

anion..$^{20}$ Since the dianions 10 are very easily deuteronated by the solvent $\left(\left[\mathrm{D}_{10}\right] \mathrm{DME}\right),{ }^{22}$ the spectroscopically determined amounts of the respective dianions $\mathbf{1 0}$ are not absolute values. In the case of the parent hydrocarbon $\mathbf{4 a}$ and the benzhydryl derivative $4 \mathrm{e}$, the respective dianions $10 \mathrm{a}$ and $10 \mathrm{e}$ were not observed at all. For better comparison, therefore, the combined relative abundances of the mono- and dianions 8 and $\mathbf{1 0}$ have to be related to those of the elimination product, i.e., dianion $\mathbf{5 - K _ { 2 }}$. In fact, the relative abundances of $\mathbf{5}-\mathbf{K}_{\mathbf{2}}$ versus those of 8 plus 10 correlate with the relative stabilities of the expelled anions, i.e., $\mathrm{H}^{-} \gg \mathrm{Bn}^{-}>\mathrm{Me}^{-}>\mathrm{Et}^{-}$. At first glance, the benzhydryl substituent should be eliminated even more easily than the benzyl substituent from $4 \mathbf{d}$ as the anion $\mathrm{Ph}_{2} \mathrm{CH}^{-}$is highly stabilized; in contrast, though, the relative abundance of $\mathbf{5}-\mathbf{K}_{\mathbf{2}}$ is particularly low in the mixture obtained from $\mathbf{4 e}$. In this case, however, deprotonation of the benzhydrylic $\mathrm{C}-\mathrm{H}$ bond competes with the deprotonation of the bridgehead positions in $4 \mathbf{e}$, to generate monoanion 8 $\mathbf{e}^{\prime}$ (Figure 1). Subsequent deprotonation of a bridgehead $\mathrm{C}-\mathrm{H}$ bond of $8 \mathbf{e}^{\prime}$ gives dianion $10 \mathbf{e}^{\prime}$ (Figure 1) which is isomeric with 10e. After subsequent deprotonation the postulated trianion $9 \mathrm{e}$ does not fragment, since the leaving group would have to be the particularly poor diphenylmethylidene dianion $\mathrm{Ph}_{2} \mathrm{C}^{2-}$.

Obviously, the formation of dianion $\mathbf{5}-\mathbf{K}_{\mathbf{2}}$ is very favorable owing to its inherent stability. Accordingly, the overall deprotonation-elimination process was found to be irreversible. The negative charge is distributed symmetrically over the whole $\pi$-electron system of the dianion $\mathbf{5}$ as clearly reflected by X-ray structure analysis and ${ }^{1} \mathrm{H}$ NMR spectroscopy (see Figures 4-6).

On the basis of these results, the suggested mechanism for the formation of the dipotassium tribenzacepentalene dianion (5-K $\mathbf{K}_{\mathbf{2}}$ ) comprises three consecutive deprotonation steps leading, via $\mathbf{8}$ and $\mathbf{1 0}$, to the corresponding trianionic salts 9 . Owing to the high density of negative charge, these species should be extremely short-lived and undergo a fast elimination of the central substituent as a hydride or a carbanion, respectively (Scheme 2). ${ }^{21}$ As a consequence, the concentrations of the trianions 9 are too low to be directly observed by NMR spectroscopy.

(19) For recent papers on centrotriindans and higher centropolyindans, see: (a) Kuck, D.; Eckrich, R.; Tellenbröker, J. J. Org. Chem. 1994, 59, 2511-2515. (b) Kuck, D.; Paisdor, B.; Gestmann, D. Angew. Chem. 1994 106, 1326-1328; Angew. Chem., Int. Ed. Engl. 1994, 33, 1251-1253. (c) Kuck, D.; Schuster, A.; Paisdor, B. J. Chem. Soc., Perkin Trans. 1 1995, 721-732. (d) Kuck, D.; Schuster, A.; Gestmann, D.; Posteher, F.; Pritzkow, H. Chem-Eur. J., in press.

(20) Haag, R.: Kuck, D.; Fu, X.-Y., Cook, J. M.; de Meijere, A. Synlett 1994, $340-342$.

(21) Currie, G. J.; Bowie, J. H.; Massay-Westropp, R. A.; Adams, G. W. J. Chem. Soc, Perkin Trans. 2 1988, 403.

(22) The dianions $10 a-e$ abstract deuterons from the solvent $\left[D_{10}\right] D M E$ to give the corresponding monoanions $8 \mathrm{a}-\mathrm{e}\left(t_{1 / 2}<1 \mathrm{~h}\right.$ at $\left.25^{\circ} \mathrm{C}\right)$.
Table 2. 1,10-Disubstituted Tribenzotriquinacene Derivatives 11, Obtained by Reaction of Monoanion $\mathbf{8 b}$ with Electrophiles

\begin{tabular}{cllc}
\hline product & substituent $\mathrm{R}$ & \multicolumn{1}{c}{ reagent $\mathrm{RX}$} & yield $(\%)$ \\
\hline $\mathbf{1 1 a}$ & $\mathrm{CH}_{3}$ & $\left(\mathrm{H}_{3} \mathrm{CO}\right)_{2} \mathrm{SO}_{2}$ & 52 \\
$\mathbf{1 1 b}$ & $\mathrm{C}_{2} \mathrm{H}_{5}$ & $\left(\mathrm{H}_{5} \mathrm{C}_{2} \mathrm{O}\right)_{2} \mathrm{SO}_{2}$ & 66 \\
$\mathbf{1 1 c}$ & $n-\mathrm{C}_{6} \mathrm{H}_{13}$ & $n-\mathrm{C}_{6} \mathrm{H}_{13} \mathrm{Br}$ & 65 \\
11d & $\mathrm{Si}\left(\mathrm{CH}_{3}\right)_{3}$ & $\mathrm{ClSi}\left(\mathrm{CH}_{3}\right)_{3}$ & 89 \\
\hline
\end{tabular}

\section{Scheme $3^{a}$}

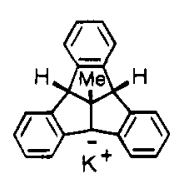

$\mathbf{8 b}$

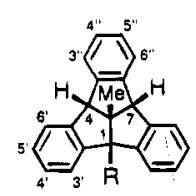

$11 a-d$ a For yields see Table 2.

\section{Scheme 4}

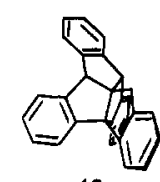

12
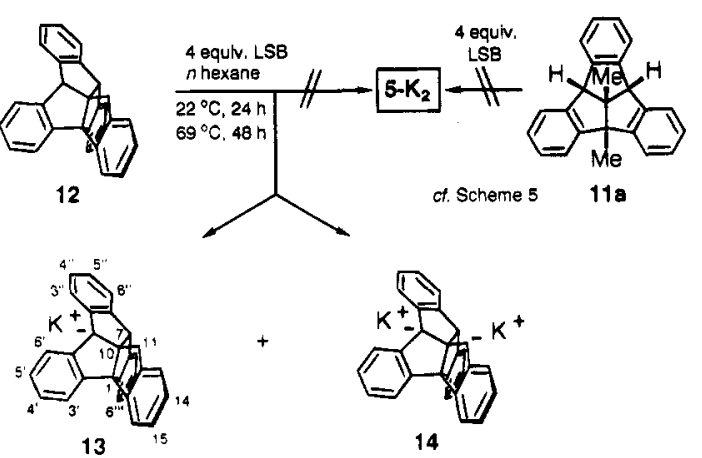

According to this mechanism, the monopotassium salts 8 can also be prepared highly selectively by using $1.0-1.25$ equiv of LSB. In these experiments, the temperature was kept at $40^{\circ} \mathrm{C}$ to avoid formation of the elimination product, which is favored at elevated temperatures.

The reaction of the methyl-substituted monoanion $8 \mathbf{b}$ with various electrophiles (Table 2) yields the corresponding 1,10disubstituted tribenzotriquinacenes 11a- $\mathbf{d}$ in good yields (Scheme 3 , Table 2). Hence, the use of LSB offers an interesting access to a variety of partially- and fully-bridgehead-substituted tribenzotriquinacenes. ${ }^{23,24}$ The 1,10-dimethyl derivative 11a, in particular, represents the tribenzo analogue of 1,10-dimethyltriquinacene described recently by Cook et al. ${ }^{25}$

The postulated mechanism (Scheme 2) is further corroborated by the fact that 1,10-dialkyl-substituted tribenzotriquinacenes did not undergo the deprotonation-elimination reaction at all. Thus, centrotetraindan $12,{ }^{26}$ when treated with 4 equiv of LSB under the same conditions as for $4\left(24 \mathrm{~h}\right.$ at $22^{\circ} \mathrm{C}, 48 \mathrm{~h}$ at 69 ${ }^{\circ} \mathrm{C}$ ), gave only the singly and doubly deprotonated species $\mathbf{1 3}$ and 14 (Scheme 4), as observed by ${ }^{1} \mathrm{H}$ NMR spectroscopy; the signals of the 1,10-elimination product $\mathbf{5} \cdot \mathbf{K}_{\mathbf{2}}$ were not found. ${ }^{27}$ In addition, careful quenching of the anion mixture with water

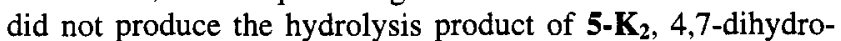
tribenzacepentalene (6a), or its dimer, 22 (see below, Scheme

(23) (a) Schuster, A.: Kuck, D. Angew. Chem. 1991, 103, 1717-1720; Angew. Chem., Int. Ed. Engl. 1991, 30, 1699-1702. (b) Schuster, A.; Kuck, D. Manuscript in preparation. (c) Schuster, A. Dissertation, Universität Bielefeld, 1991.

(24) Kuck, D.; Schuster, A.; Fusco, C.; Fiorentino, M.; Curci, R. J. Am. Chem. Sac. 1994, 116, 2375-2381.

(25) 1,10-Disubstituted triquinacenes have been prepared by the "Weiss" reaction: (a) Gupta, A. K.; Weiss, U.; Cook, J. M. Tetrahedron Lett. 1988, 2535-2538. (b) Gupta, A. K.; Fu, X.; Snyder, J. P.; Cook, J. M. Tetrahedron 1991, 47, 3665-3710. See also ref le.

(26) Kuck, D.; Seifert, M. Chem. Ber. 1992, 125, 1461-1469.

(27) No 2 -fold bridgehead dianion was observed upon deprotonation of 12, indicating that the bridgehead benzhydrylic $\mathrm{C}-\mathrm{H}$ bonds and the (nonbridgehead) benzylic $\mathrm{C}-\mathrm{H}$ bonds of 12 have similar acidities. 
Scheme 5

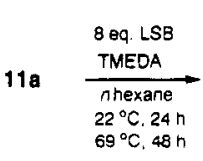

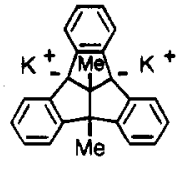

15

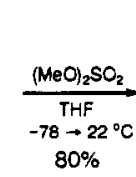

$80 \%$

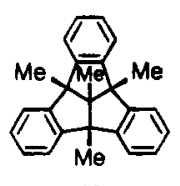

16
11). In this case, only the starting material $\mathbf{1 2}$ was recovered in almost quantitative yield. Obviously, the third deprotonation step, which is blocked by the presence of a substituent at one of the three peripheral bridgehead positions, is essential for the formation of dianion $\mathbf{5} \cdot \mathbf{K}_{\mathbf{2}}$. With regard to the facile deprotonation of $4 e$ at the central substituent (Figure 1), the competing deprotonation of the benzylic methylene group in $\mathbf{1 2}$ may additionally prevent the cleavage of the central (exocyclic) $\mathrm{C}-\mathrm{C}$ bond.

Treatment of 1,10-dimethyltribenzotriquinacene (11a) with a large excess (8 equiv of LSB and TMEDA as cosolvent ${ }^{28 a}$ ) of LSB did not lead to a deprotonation-elimination reaction either. Instead, efficient 2-fold deprotonation was achieved in this case, as revealed by subsequent trapping of the dianion $\mathbf{1 5}$ (inverse addition) with dimethyl sulfate to give 1,4,7,10tetramethyltribenzotriquinacene (16) in $80 \%$ isolated yield (Scheme 5). This strongly corroborates the necessity of the formation of trianions 9 as key intermediates in the overall deprotonation-elimination process $\mathbf{4} \rightarrow \mathbf{5}-\mathbf{K}_{\mathbf{2}}$.

The efficient two-step synthesis of the sterically congested tetramethyltribenzotriquinacene (16) via the dimethyl analogue $11 \mathrm{a}$ is an interesting alternative to the previously reported preparation ${ }^{23}$ by 3 -fold bromination of $4 \mathbf{b}$ and treatment of the resulting 1,4,7-tribromo-10-methyltribenzotriquinacene ${ }^{19 \mathrm{c}}$ with trimethylaluminum, ${ }^{29}$ furnishing 16 in $94 \%$ yield.

Chemical and Structural Features of 4,7-Disubstituted Tribenzodihydroacepentalene Derivatives 6. As pointed out above, there are various possibilities to introduce up to four substituents at the bridgehead positions on the convex side of the tribenzotriquinacene framework. By combining bridgehead substitution with 1,10-elimination, tribenzotriquinacenes are easily converted to the corresponding 4,7-disubstituted tribenzodihydroacepentalenes 6 . In a formal parallel to the alternative routes to the tetramethyl derivative 16 (see above), two complementary approaches may be used here: (i) the substitution-elimination path, i.e., bridgehead bromination followed by elimination of hydrogen bromide from one of the central $\mathrm{C}-\mathrm{C}$ bonds with concomitant nucleophilic substitution at the other bridgehead positions, and (ii) the deprotonation-elimination path, i.e., formation of dianion $\mathbf{5}-\mathbf{K}_{\mathbf{2}}$ with LSB and subsequent attack by suitable electrophiles. Both of these approaches have parallels in the parent triquinacene chemistry. $1 \mathrm{f}, 4,12,30$

Similar to the centro-methyl derivative $\mathbf{4 b}$, the unsubstituted tribenzotriquinacene (4a) can be converted by radical-induced bromination to the 1,4,7-derivative $\mathbf{1 7}$ in almost quantitative yield. ${ }^{23}$ Subsequent treatment with morpholine gives the $4,7-$ bis(morpholino)tribenzodihydroacepentalene derivative (6b) in $82 \%$ yield (Scheme 6), in analogy to previous results. ${ }^{23,30}$ For

(28) (a) TMEDA ( $N, N, N^{\prime}, N^{\prime}$-tetramethylethylenediamine) was used as a cosolvent for homogenous reactions with Lochmann-Schlosser base see: Brandsma, L.; Verkruijsse, H. D.; Schade, C.; Schleyer, P. v. R. J. Chem. Soc. Chem. Commun. 1986, 260-261 and literature cited therein (b) For LSB ${ }^{\text {hs }}$ (hexane soluble Lochmann-Schlosser base), see: Lochmann, L.; Trekoval, J. J. Organomet. Chem. 1987, 326, 1-7.

(29) For a related application, see: Kuck, D.; Schuster, A.; Krause, R. A. J. Org. Chem. 1991, 56, 3472-3475.

(30) (a) Butenschön, H.; de Meijere, A. Tetrahedron Lett. 1983, 45634566. (b) Butenschön, H.; de Meijere, A. Tetrahedron Lett. 1984, $1693-$ 1696. (c) Butenschön, H.; de Meijere, A. Chem. Ber, 1985, 118, 25572776.
Scheme 6
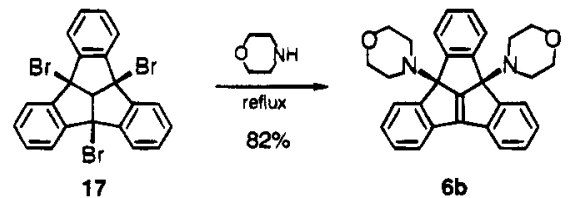

Scheme $7^{a}$
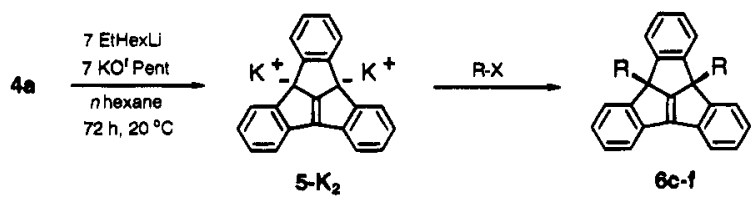

${ }^{a}$ For yields and conditions see Table 3 .

Table 3. Conditions and Yields for the Formation of 4,7-Disubstituted Tribenzodihydroacepentalenes $6 \mathbf{c}-\mathbf{f}$

\begin{tabular}{ccccc}
\hline compound & substituent $\mathrm{R}$ & reagent $\mathrm{RX}$ & conditions & yield (\%) \\
\hline 6c & $\mathrm{Si}\left(\mathrm{CH}_{3}\right)_{3}$ & $\mathrm{ClSi}\left(\mathrm{CH}_{3}\right)_{3}$ & $\begin{array}{c}\text { hexane, } \\
-78 \rightarrow+20\end{array}$ & 96 \\
6d & $\mathrm{CO}_{2} \mathrm{CH}_{3}$ & $\mathrm{ClCO}_{2} \mathrm{CH}_{3}$ & $\begin{array}{c}\mathrm{THF} / \text { hexane, } \\
-78 \rightarrow+20\end{array}$ & 58 \\
6e & $\mathrm{SeC}_{6} \mathrm{H}_{5}$ & $\mathrm{ClSeC}_{6} \mathrm{H}_{5}$ & $\begin{array}{c}\mathrm{THF} / \text { hexane, } \\
-78 \rightarrow+20\end{array}$ & 17 \\
6f & $\mathrm{Sn}\left(\mathrm{CH}_{3}\right)_{3}$ & $\mathrm{ClSn}\left(\mathrm{CH}_{3}\right)_{3}$ & $\begin{array}{c}{ }^{\circ} \mathrm{C} \\
\text { hexane, } \\
-78 \rightarrow 0\end{array}$ \\
& & & ${ }^{\circ} \mathrm{C}$ & 42 \\
\hline
\end{tabular}

the parent triquinacene derivatives, the mechanism of this reaction was found ${ }^{30}$ to be a 2 -fold substitution by morpholine with concomitant elimination of $\mathrm{HBr}$; this same mechanism should operate in the tribenzo series as well. However, this substitution-elimination sequence from tribromide $\mathbf{1 7}$ is limited to the synthesis of 4,7-diaminotribenzodihydroacepentalenes 6 .

The deprotonation-elimination route turned out to be more versatile. Thus, treatment of tribenzotriquinacene (4a) with an excess of $n$-hexane soluble Lochmann-Schlosser base (LSB ${ }^{\text {hs }},{ }^{28 b}$ an equimolar mixture of (2-ethylhexyl)lithium and potassium tert-pentoxide, gave a single product in quantitative yield, viz., dipotassium tribenzacepentalenediide $\left(\mathbf{5} \cdot \mathbf{K}_{2}\right)$ (Scheme 7). The strongly basic mixture $\mathrm{LSB}^{\mathrm{hs}}$ can only be used at room temperature $\left(20^{\circ} \mathrm{C}\right)$ or below, because it decomposes at higher temperatures. Most remarkably, the hydride elimination from the trianionic intermediate $9 \mathbf{a}$ (cf. Scheme 2) occurs already at room temperature. This unusually low temperature for hydride elimination reactions ${ }^{10}$ emphasizes the facile formation of the resonance-stabilized dianion $\mathbf{5}-\mathbf{K}_{\mathbf{2}}$. It is also noteworthy that this highly efficient process did not take place for the centrosubstituted tribenzotriquinacenes $\mathbf{4 b}-\mathbf{e}$; these compounds, however, were readily transformed into $\mathbf{5}-\mathbf{K}_{\mathbf{2}}$ under heterogeneous conditions, as described above, or in the presence of TMEDA as a cosolvent ${ }^{28 a}$ at elevated temperatures $\left(69^{\circ} \mathrm{C}\right) .^{20}$ In both cases, tribenzacepentalene dianion $\mathbf{5}-\mathbf{K}_{\mathbf{2}}$ was trapped with various electrophiles to give 4,7-disubstituted tribenzodihydroacepentalenes 6 in high yields. For example, the 4,7-bis(trimethylsilyl) derivative $\mathbf{6 c}$ was obtained in excellent yield by reacting $\mathbf{5}-\mathbf{K}_{\mathbf{2}}$ with chlorotrimethylsilane (Table 3). ${ }^{13,31}$ Although not tested explicitly, it is obvious that this method opens an independent synthetic access to a broad variety of 4,7. dihetero-substituted tribenzodihydroacepentalenes 6.

In contrast to the rather stable 4,7-bis(dialkylamino)tribenzodihydroacepentalenes such as $\mathbf{6 b}$ and the corresponding dimethylamino analogue, ${ }^{23 a}$ the new disubstituted derivatives $\mathbf{6 c}-\mathbf{f}$ are unstable at room temperature or easily add electrophiles across the central bridgehead-bridgehead double bond. The

(31) Haag, R.; Ohlhorst, B.; Noltemeyer, M.; Schuster, A.; Kuck, D.; de Meijere, A. J. Chem. Soc., Chem. Commun. 1993, 1727-1729. For IUPAC nomenclature of compounds 4 and 6 see also refs 14 and 23 . 
Table 4. Influence of Substituents on the Central Bond Lengths and Interplanar Angles in 4,7-Disubstituted Tribenzodihydroacepentalene Derivatives $\mathbf{6 b}-\mathbf{d}(c f \text {. Figure } 2)^{31}$

\begin{tabular}{lccc}
\hline & $\begin{array}{c}\text { 6b } \\
(\mathrm{R}=\text { morpholine })\end{array}$ & $\begin{array}{c}\mathbf{6 c} \\
\mathrm{R}=\mathrm{TMS})\end{array}$ & $\begin{array}{c}\mathbf{6 d} \\
\left.\mathrm{C}=\mathrm{CO}_{2} \mathrm{Me}\right)\end{array}$ \\
\hline $\begin{array}{l}\text { bond lengths } \\
\mathrm{C}(1)=\mathrm{C}(10)(\mathrm{pm})\end{array}$ & $134.5(4)$ & $134.5(6)$ & $135.6(5)$ \\
$\mathrm{C}(1)-\mathrm{C}(2)(\mathrm{pm})$ & $146.9(4)$ & $146.0(6)$ & $147.0(6)$ \\
angles between & & & \\
planes A/B $\mathbf{B}^{a}(\mathrm{deg})$ & $36.5(2)$ & $36.2(3)$ & $33.8(3)$ \\
plane $\mathbf{C} /$ axis & $47.2(3)$ & $40.4(3)$ & $45.8(5)$ \\
$\begin{array}{l}\mathrm{C}(1)=\mathrm{C}(10)^{b}(\mathrm{deg}) \\
\text { plane } \mathbf{D} / \text { axis }\end{array}$ & $30.2(2)$ & $37.0(3)$ & $27.6(4)$ \\
$\mathrm{C}(1)=\mathrm{C}(10)^{c}(\mathrm{deg})$ & & & \\
\hline
\end{tabular}

${ }^{a}$ Angle between plane $\mathrm{A}(\mathrm{C} 2-\mathrm{C} 1-\mathrm{C} 10-\mathrm{C} 4)$ and plane $\mathrm{B}(\mathrm{C} 9-$ $\mathrm{C} 1-\mathrm{C} 10-\mathrm{C} 7) .{ }^{b}$ Plane $\mathrm{C}(\mathrm{C} 4-\mathrm{C} 7-\mathrm{C} 10) .{ }^{c}$ Plane $\mathbf{D}(\mathrm{C} 1-\mathrm{C} 2-\mathrm{C} 9)$.

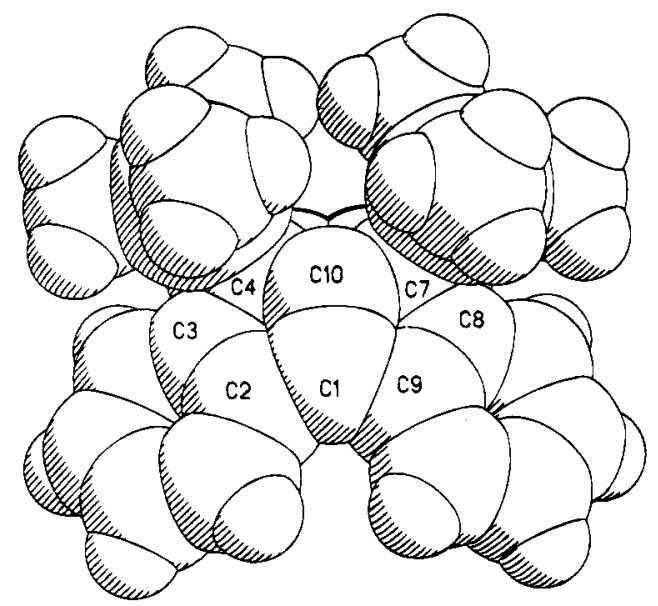

Figure 2. Space filling model of 4,7-bis(trimethylsilyl)tribenzodihydroacepentalene $(\mathbf{6 c})$ as viewed onto its highly pyramidalized $\mathrm{C}(1)=\mathrm{C}(10)$ double bond.

degree of stability is reflected by the isolated yields of these compounds (Table 3). In particular, the bis(trimethylstannyl) derivative $6 f$ is highly sensitive toward light, air, and water. Due to its sensitivity, the purification of this compound was not easy, but was achieved eventually by low-temperature $(-30$ ${ }^{\circ} \mathrm{C}$ ) crystallization from $n$-hexane. The ${ }^{1} \mathrm{H}$ NMR spectrum of 6f was almost identical to that of the bis(trimethylsilyl) derivative 6c. Also, the EI mass spectrum with the correct isotopic pattern clearly confirmed the molecular formula $\mathrm{C}_{28} \mathrm{H}_{30^{-}}$ $\mathrm{Sn}_{2}$.

The observed lability of compounds $6 c-f$ is certainly due to the severe pyramidalization of the central $\mathrm{C}(1)=\mathrm{C}(10)$ double bonds. Therefore, suitable crystals of three tribenzodihydroacepentalenes, $\mathbf{6 b}-\mathbf{d}$, were subjected to $\mathrm{X}$-ray structure analysis with particular attention to the degree of pyramidalization around $\mathrm{C}(1)$ and $\mathrm{C}(10)$ (Table 4), 2,31,32 In some cases, viz., 6b and $\mathbf{6 d}$ (Figure 2), one of the two out-of-plane angles was found to exceed those calculated for the highly symmetrical dodecahedradiene $\left(42.9^{\circ}\right.$ both $),{ }^{33}$ which is one of the most highly pyramidalized, yet isolable olefins. The total out-of-plane bending of the four $C-C$ bonds at the $C(1)-C(10)$ axis is very similar for both $6 \mathbf{b}$ and $6 \mathbf{c}$, with the sum of the angles at $\mathrm{C}(1)$ and $\mathrm{C}(10)$ amounting to $77.4^{\circ} \pm 0.5^{\circ}$ but falling short of the corresponding sum of angles for dodecahedrene $\left(85.8^{\circ}\right)$.

It is most intriguing that even the highly shielded bis(trimethylsilyl) derivative 6c (Figure 2 ) readily adds water or methanol under acid catalysis at 50 or $20^{\circ} \mathrm{C}$, respectively, across

(32) For a review on pyramidalized alkenes, see e.g.: (a) Borden, W. T. Chem. Rev. 1989, 89, 1095-1109. (b) Luef, W.; Keese, R. Top. Stereochem 1991, 20, 231-318. See also ref 2 .

(33) Melder, J.-P.; Pinkos, R.; Fritz, H.; Prinzbach, H. Angew. Chem. 1990, 102, 105-109; Angew. Chem., Int. Ed. Engl. 1990, 29, 95-99.
Scheme 8

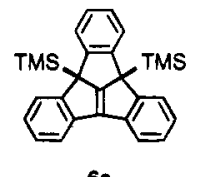

$6 \mathrm{c}$

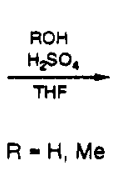

$R=H, M e$

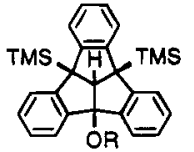

18 a: $R=H, 62 \%$ b: $R=M e, 71 \%$
19

Scheme 9

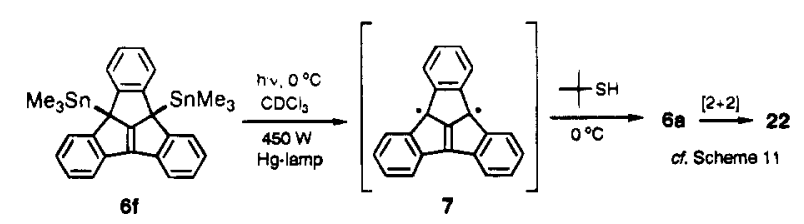

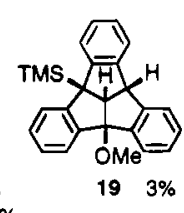

its highly bent central double bond. The trisubstituted tribenzotriquinacenes 18 were obtained in good yields (Scheme 8) and represent some new congeners among the very rare tribenzotriquinacenes bearing different bridgehead substituents. ${ }^{23}$ Treatment of $\mathbf{6 c}$ with methanol produced, besides the major adduct $\mathbf{1 8 b}$, the side product 19 which was isolated in low yield (3\%).

Properties of the Unstable 4,7-Bis(trimethylstannyl)tribenzodihydroacepentalene (6f). The EI mass spectrum of compound $\mathbf{6 f}$ is dominated by a peak at $\mathrm{m} / \mathrm{z}=276(100 \%$ relative intensity) corresponding to the loss of the two bridgehead substituents. High-resolution measurements of this peak confirm the formula $\mathrm{C}_{22} \mathrm{H}_{12}{ }^{\text {}+}$ for the corresponding fragment ion, and subsequent fragmentation of this species appears to be negligible. It is therefore proposed to be the radical cation of tribenzacepentalene $\left(7^{\bullet+}\right)$. The same fragment ion peak is also observed in the EI mass spectra of all other 4,7-disubstituted tribenzodihydroacepentalene derivatives $6 b-e$, and even the mass spectra of many tri- and tetrasubstituted tribenzotriquinacenes such as $\mathbf{1 7}^{23 a, c}$ and 1,4,7-tribromo-10-methyltribenzotriquinacene ${ }^{23 b, c}$ exhibit prominent peaks at $m / z=276$. Most remarkable in this regard is the spectrum of tribromotribenzotriquinacene (17), which shows not only the formation of the singly charged $\mathrm{C}_{22} \mathrm{H}_{12}{ }^{\text {}}{ }^{+}$ions (ca. $70 \%$ ) but also the presence of the doubly charged species $\mathrm{C}_{22} \mathrm{H}_{12}{ }^{2+}$ at $\mathrm{m} / \mathrm{z}=138$. ${ }^{23 \mathrm{c}}$

Irradiation of $\mathbf{6 f}$ with a high-pressure mercury lamp resulted in decomposition products and formation of hexamethyldistannane (Scheme 9). When tert-butyl mercaptan was added prior to irradiation, the characteristic bridgehead proton signal of the 4,7-dihydrotribenzacepentalene dimer (22) was observed in the ${ }^{1} \mathrm{H}$ NMR spectrum of the crude product mixture ( $c f$. Scheme 11). Admittedly, however, one can only speculate at this point as to whether the decomposition of $\mathbf{6 f}$ under these conditions proceeds via the neutral tribenzacepentalene (7) or, alternatively, via the mono(trimethylstannyl)tribenzodihydroacepentalene.

Treatment of the 4,7-bis(trimethylstannyl) derivative $6 \mathrm{f}$ with methyllithium in dimethoxyethane (DME) at $-60^{\circ} \mathrm{C}$ leads to the pure dilithium tribenzacepentalenediide $\left(\mathbf{5}-\mathbf{L i}_{2}\right)$ by a cleanly proceeding transmetalation (Scheme 10).

Structural Properties of the Dilithium Tribenzacepentalenediide $\left(5-\mathbf{L i}_{\mathbf{2}}\right)$. Dilithium tribenzacepentalenediide $\left(\mathbf{5}-\mathbf{L i}_{\mathbf{2}}\right)$ crystallized very well from a DME solution at $-30^{\circ} \mathrm{C}$. Singlecrystal structure analysis was performed at $153 \mathrm{~K}^{34}$ In contrast to the parent dilithium acepentalenediide $(\mathbf{2}-\mathbf{L i})^{35}$ and many other lithium salts of conjugated hydrocarbons which form

(34) (a) Kottke, T.; Stalke, D. J. Appl. Crystallogr. 1994, 26, 615-619. (b) Kottke, T. Dissertation, Universität Göttingen, 1993

(35) Haag, R.; Fleischer, R.; Stalke, D.; de Meijere, A. Angew. Chem. 1995, 107, 1642-1644; Angew. Chem., Int. Ed. Engl. 1995, 34, 14921495 . 
Scheme 10

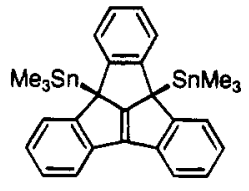

$6 f$

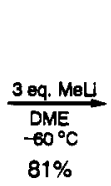

$81 \%$

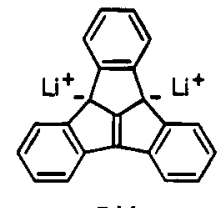

$5-\mathrm{Ll}_{2}$
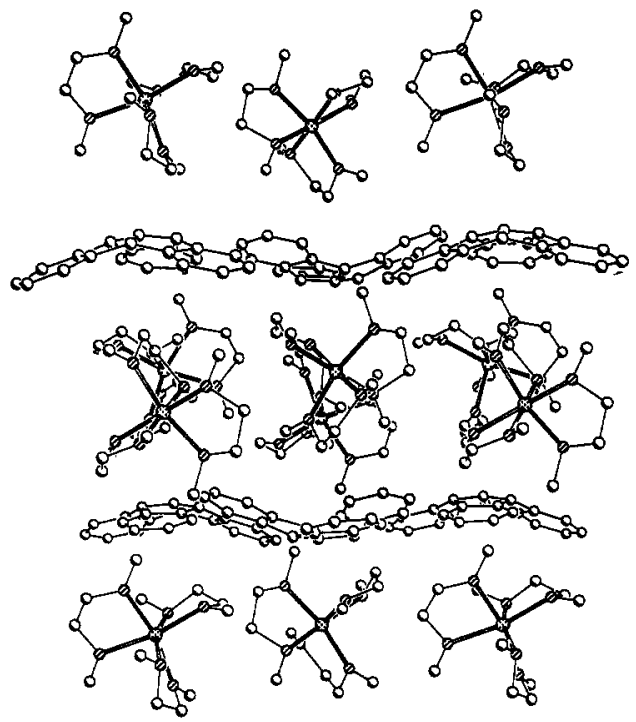

Figure 3. Packing diagram of dilithium tribenzacepentalenediide (5. $\mathbf{L i}_{2}$ ) depicting the alternating layers of dianions $\mathbf{5}$ and solvent-separated lithium cations $\left(\mathrm{Li}^{+} \cdot 3 \mathrm{DME}\right)$.

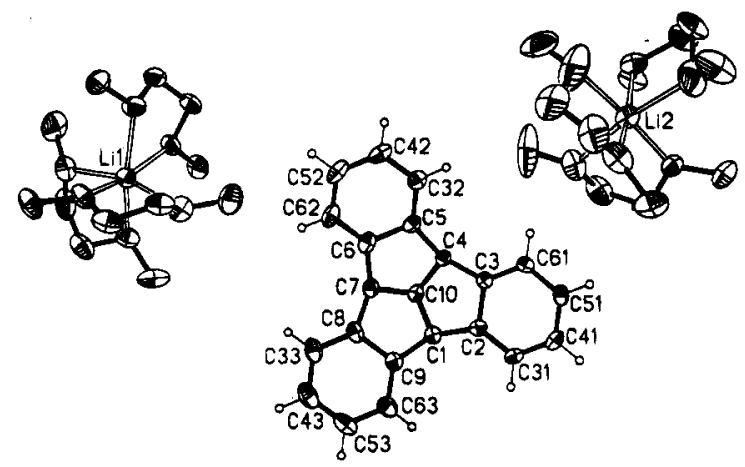

Figure 4. Structural parameters of the $\mathrm{CH}$ skeleton of $\mathbf{5}-\mathbf{L i}_{\mathbf{2}}$. Geometrically equivalent bond lengths and angles have been averaged: $\mathrm{Cl}-$ $\mathrm{C} 2,145.7 \mathrm{pm} ; \mathrm{C} 1-\mathrm{C} 10,139.7 \mathrm{pm} ; \mathrm{C} 2-\mathrm{C} 3,148.3 \mathrm{pm} ; \mathrm{C} 1-\mathrm{C} 4-\mathrm{C} 10$, $117.7^{\circ} ; \mathrm{C} 3-\mathrm{C} 4-\mathrm{C} 5,143.4^{\circ}$

contact ion pairs or triplets, ${ }^{36}$ dilithium tribenzacepentalenediide $\left(\mathbf{5}-\mathbf{L i}_{2}\right)$ was found to be a solvent-separated ion triplet in the crystal. Layers of dianions 5 alternate with layers of DMEcomplexed lithium counterions (Figure 3 ). The average distance between the dianion layers is $860 \mathrm{pm}$. Each lithium cation is chelated by three DME molecules.

The central acepentalene fragment in 5 adopts local $C_{3}$ symmetry with $C(10)$ on the 3 -fold axis (Figure 4$){ }^{37}$ The molecule is not flat but considerably bent, giving rise to a bowl

(36) (a) Streitwieser A., Jr.; Swanson, J. T. J. Am. Chem. Soc. 1983, 105, 2502-2503. (b) Streitwieser A., Jr. Acc. Chem. Res. 1984, 17, 353357. (c) Cohen, Y.; Klein, J.; Rabinovitz, M. J. Chem. Soc., Chem. Commun. 1986, 1071-1073. (d) Sygula, A.; Lipkowitz, K.; Rabideau, P. W. J. Am. Chem. Soc. 1987, 109, 6602-6605. (e) Wind, B.; Sygula, A.; Govindarajan, U.; Edlund, U.; Sethson, I.; Rabideau, P. W. J. Org. Chem. 1991, 56, 618623. (f) Sethson I.; Johnels, D.; Lejon. T.; Edlund, U.; Wind, B.; Sygula, A.; Rabideau, P. W. J. Am. Chem. Soc. 1992, 114, 953-959.

(37) This is consistent with, but not necessarily a proof, for a Y-type conjugation as suggested for the trimethylenemethane dianion and related systems: (a) Gund, P.; J. Chem. Educ. 1972, 49, 100. (b) Klein, J.; Medlik, A. J. Chem. Soc., Chem. Commun. 1973, 275. See also ref 6 .
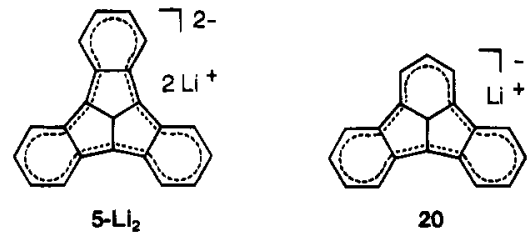

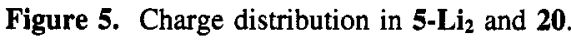

shape, ${ }^{38}$ as indicated by the sum of the central bond angles which is $353.1^{\circ}$. However, all three indan subunits are almost ideally planar with a maximum deviation of only $3 \mathrm{pm}$ from the best plane in each case. All three central $\mathrm{C}-\mathrm{C}$ bonds originating at $\mathrm{C}(10)$ are equal within their standard deviations (average 139.7 $\mathrm{pm}){ }^{37}$ The six bonds connecting the bridgeheads $\mathrm{C}(1), \mathrm{C}(4)$, and $C(7)$ to the benzene rings exceed the central ones by $6 \mathrm{pm}$ (average $145.7 \mathrm{pm}$ ). The central fragment of tribenzacepentalenediide $\mathbf{5} \cdot \mathbf{L i}_{\mathbf{2}}$ is structurally very similar to the parent compound $\mathbf{2}-\mathbf{L i}_{2}$. 35

But the three bonds which are common to one five- and one six-membered ring each are unusually long (average $148.3 \mathrm{pm}$ ), while all the other six-membered ring bonds are close to the ones in benzene ranging from 139.2 to $139.8 \mathrm{pm}$. A similar bond lengthening has been observed for the corresponding bonds in lithium $7 \mathrm{~b} H$-indeno[1,2,3-jk]fluorenide (20), ${ }^{39}$ which were found to be $146.7 \mathrm{pm}$ (average). The bond length of $148.3 \mathrm{pm}$ found here is even $1.7 \mathrm{pm}$ longer than the one for a typical $\mathrm{C}\left(\mathrm{sp}^{2}\right)-\mathrm{C}\left(\mathrm{sp}^{2}\right)$ single bond. ${ }^{40}$ Hence, this value indicates an extended distribution of negative charge over the whole $\mathrm{C}_{21}$ annulene perimeter of dianion 5 (Figure 5).

Such a delocalization would cause a partial positive charge in the center of the molecule. In fact, the ${ }^{13} \mathrm{C}$ NMR chemical shift $(\delta=177.0 \mathrm{ppm})$ of the central carbon in dilithium tribenzacepentalenediide $\left(\mathbf{5}-\mathbf{L i}_{2}\right)$ correlates well with a partial positive charge at $\mathrm{C}(10)$. The ${ }^{1} \mathrm{H}$ NMR chemical shifts (see Figure 6) of $\delta=6.55$ and $7.58 \mathrm{ppm}$ also corroborate an extended negatively charged aromatic system, $\mathbf{5}-\mathbf{L i}_{2}$, with $C_{3 v}$ symmetry as indicated in Figure 5. Accordingly, only five lines were found in the ${ }^{13} \mathrm{C}$ NMR spectrum of 5-Li $\mathbf{i}_{2}$.

Reaction of Tribenzacepentalene Dianion (5) with Water. When the substituents at the bridgehead positions $C(4)$ and $C(7)$ in 6 are small $(\mathrm{R}=\mathrm{Me})$ or absent, $6 \mathrm{a}(\mathrm{R}=\mathrm{H})$, the highly bent $C(1)=C(10)$ double bond is not sufficiently shielded and the compounds cannot be isolated even below $0{ }^{\circ} \mathrm{C}$. Thus, attempted quenching of solutions containing $5-\mathbf{K}_{\mathbf{2}}$ with dimethyl sulfate, as described above for $\mathbf{8 b}$ and $\mathbf{1 5}$, did not afford the expected 4,7-dimethyltribenzodihydroacepentalene but polymeric material. However, when the solution of $\mathbf{5 - K _ { 2 }}$ was treated with water at $-78{ }^{\circ} \mathrm{C}$ and the mixture then allowed to warm to room temperature, the $[2+2]$ dimer 22 was formed and isolated in excellent yield (97\%) (Scheme 11). Moreover, the unsubstituted monomer 6a was observed by ${ }^{1} \mathrm{H}$ NMR spectroscopy when the solution was kept at $-60^{\circ} \mathrm{C}$ after quenching. The bridgehead protons of $6 \mathrm{a}$ show a characteristic singlet at $\delta=$ $4.58 \mathrm{ppm}$, which is $0.39 \mathrm{ppm}$ upfield of the corresponding bridgehead proton resonance of the "saturated" tribenzo-

(38) (a) Ayalon, A.; Rabinovitz, M.; Cheng, P.-C.; Scott, L. T. Angew. Chem. 1992, 104, 1691-1692; Angew. Chem., Int. Ed. Engl. 1992, 31, 1636-1637. (b) Ayalon, A.; Sygula, A.; Cheng, P.-C.; Rabinovitz, M.; Rabideau, P. W.; Scott, L. T. Science 1994, 265, 1065-1067. (c) Cohen, Y.; Ayalon, A. Angew. Chem. 1995, 107, 888-891; Angew. Chem., Int. Ed. Engl. 1995, 34, 816-818. (d) Sygula, A.; Folsom, H. E.; Sygula, R.; Abdourazak, A. H.; Macinow, Z.; Fronczek, F. R.; Rabideau, P. W. J. Chem Soc., Chem. Commun. 1995, 2571-2572.

(39) (a) Bladauski, D.; Dietrich, H.; Hecht, H.-J.; Rewicki, D. Angew. Chem. 1977, 89, 490-491; Angew. Chem., Int. Ed. Engl. 1977, 16, 474475. (b) Bladauski, D.; Broser, W.; Hecht, H.-J.; Rewicki, D.; Dietrich, H. Chem. Ber. 1979, 112, 1380-1391.

(40) Rademacher, P. In Strukturen organischer Moleküle; Klessinger, M., Ed,; VCH: New York, 1987; p 56. 


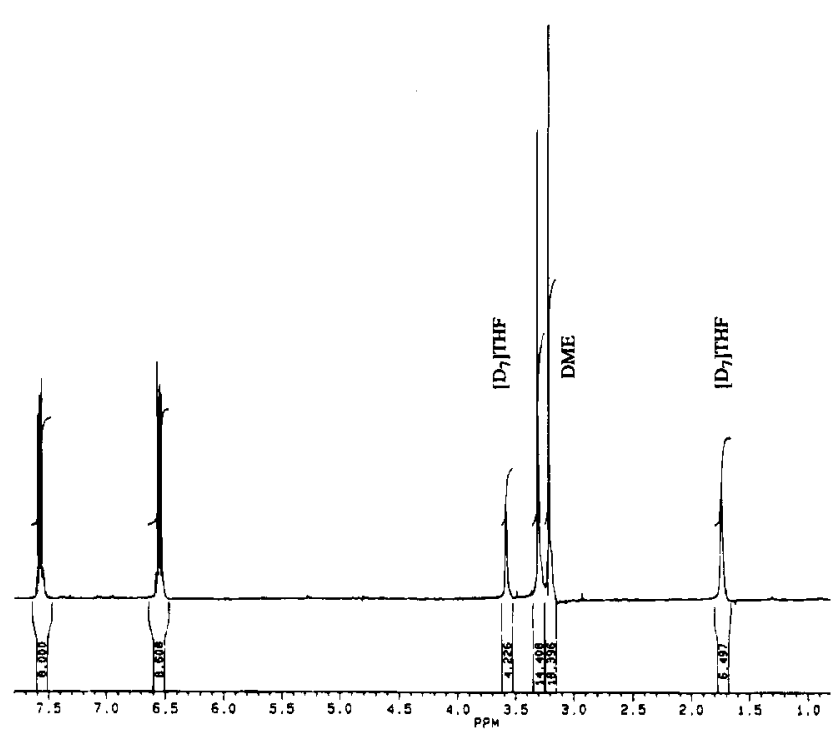

Figure 6. ${ }^{1} \mathrm{H}$ NMR spectrum of dilithium tribenzacepentalenediide $\left(5-\mathbf{L i}_{2}\right)\left(250 \mathrm{MHz},\left[\mathrm{D}_{8}\right] \mathrm{THF}\right)$ showing the line pattern of a single $\mathrm{AA}^{\prime} \mathrm{XX}^{\prime}$ spin system for the 12 arene protons.

\section{Scheme 11}

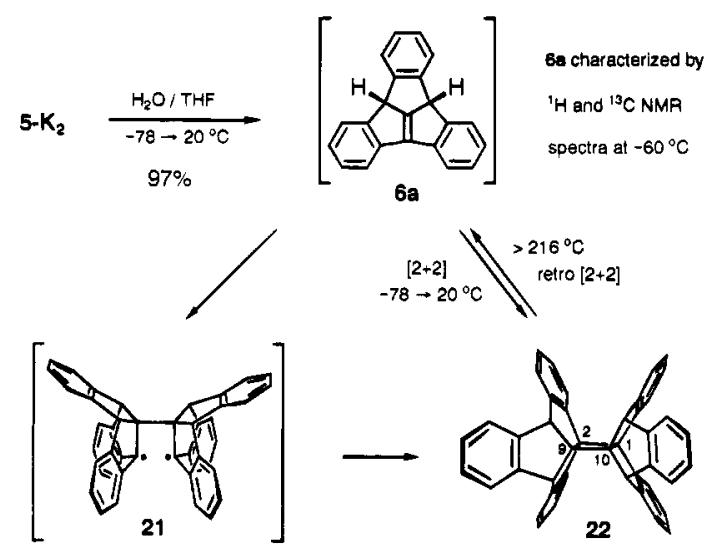

triquinacene (4a) $(\delta=4.97 \mathrm{ppm}) .^{14,41}$ The bridgehead proton resonance of dimer 22 appears at $\delta=5.23 \mathrm{ppm}, 0.75 \mathrm{ppm}$ downfield as compared to those of $4 \mathbf{b}(\delta=4.47 \mathrm{ppm})^{14,18}$ or $11 \mathrm{a}(\delta=4.48 \mathrm{ppm})$. This indicates that the bridgehead protons of the dimer 22 are deshielded by the benzene rings of the opposite moiety of the molecule. This effect can only occur in a head-to-head dimer. In fact, the near-quantitative yield of 22 suggests that dimerization $6 a \rightarrow 22$ involves the biradical intermediate $\mathbf{2 1}$ which should gain additional stability from the benzhydrylic character of the two bridgehead radical moieties. Alternatively, formation of the head-to-tail dimer would require a biradical containing a nonconjugated radical center at one of the central carbon atoms.

The X-ray structure analysis of the dimer 22 proved the headto-head orientation of the two tribenzotriquinacene moieties, as reported previously. ${ }^{31}$ Furthermore, the structure of $\mathbf{2 2}$ exhibits an unusually long lateral $\mathrm{C}(1)-\mathrm{C}(2)$ cyclobutane single bond $(160.2 \pm 0.6 \mathrm{pm})$, whereas the central $C(9)-C(10)$ bond is only slightly elongated $(156.6 \pm 0.6 \mathrm{pm})$. Hence, the former $\mathrm{C}-\mathrm{C}$ bond is ca. $4 \mathrm{pm}$ longer than usual for cyclobutane derivatives. ${ }^{42}$ This remarkable bond lengthening may be attributed to an interaction of the $\sigma^{*}$ orbitals of the $\mathrm{C}(1)-\mathrm{C}(10)$ bond and the adjacent $\pi$-orbitals of the annelated benzene rings (Figure 7).

(41) Reference 13 erroneously states incorrect ${ }^{1} \mathrm{H}$ NMR data of $4 \mathrm{a}$; for the correct ones see ref 14

(42) Cf. Prangé, T.; Pascard, C.; de Meijere, A.; Behrens, U.; Barnier, J.-P.; Conia, J.-M. Nouv. J. Chim. 1980, 4, 321-327 and references cited therein.

\section{Scheme 12}
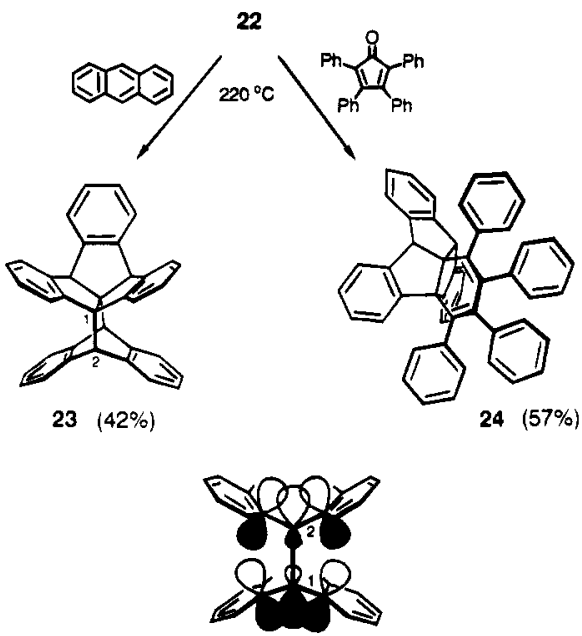

Figure 7. Adjacent $\pi$-orbitals in compounds 22 and 23 .

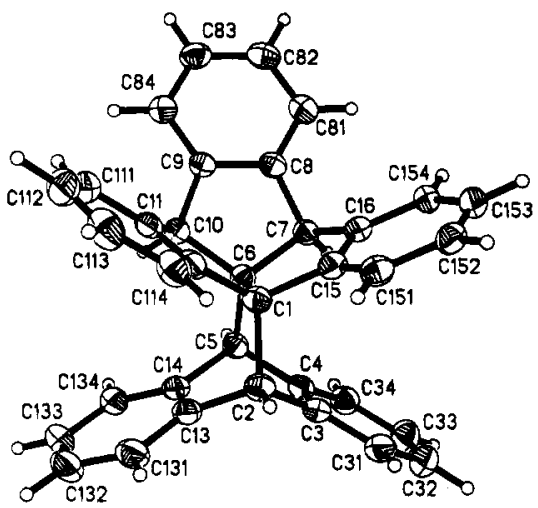

Figure 8. Crystal structure of $\mathbf{2 3}$, anisotropic displacement parameters depicting $50 \%$ probability (1.5 THF molecules present in the asymmetric unit have been omitted for clarity).

This so-called through-bond coupling was first described by Hoffmann. ${ }^{43}$ A related bond lengthening effect to even 161.8 $\mathrm{pm}$ was found recently for the central $\mathrm{C}\left(\mathrm{sp}^{3}\right)-\mathrm{C}\left(\mathrm{sp}^{3}\right)$ single bond in a diaryl-substituted tetrahydroindeno[1,2-a]indene $\left(C_{s}\right.$-diindan) and has been attributed to a similar through-bond coupling. ${ }^{44}$

The increased bond distances in the cyclobutane core of $\mathbf{2 2}$ suggested that the dimerization of $\mathbf{6 a}$ should be reversible. Indeed, differential scanning calorimetry (DSC) ${ }^{45}$ indicated an endothermic transformation conversion of dimer 22 at $216^{\circ} \mathrm{C}$, suggesting a thermal equilibrium, $6 \mathbf{a}-\mathbf{2 2}$, above this temperature. Attempts to perform a selective cleavage of the weakened $C(1)-C(2)$ single bond in 22 to regenerate and trap the diradical 21 were not successful yet. However, the reversal of the [2+ 2] cycloaddition of $\mathbf{6 a}$ can be used for the synthesis of new structurally interesting polycycles. Thus, when heated together with high-melting dienes at $220{ }^{\circ} \mathrm{C}$, dimer 22 gave the corresponding Diels-Alder adducts in good yields (Scheme 12). Reaction with anthracene gave polycycle 23 (Figure 8), containing a bicyclo[2.2.2]octatriene unit fused to one of the central $\mathrm{C}-\mathrm{C}$ bonds of the tribenzotriquinacene moiety. Like dimer 22 , the anthracene adduct 23 of $6 \mathbf{a}$ contains a rigid 1,1,2,2tetraarylethane unit, and its X-ray structure analysis again

(43) Hoffmann, R. Acc. Chem. Res. 1971, 4, 1-9 and references cited therein.

(44) Anstead, G. M.; Srinivasan, R.; Peterson, C. S.; Wilson, S. R.; Katzenellenbogen, J. A. J. Am. Chem. Soc. 1991, 113, 1378-1385.

(45) The differential scanning calorimetry (DSC) curve disclosed a small maximum at $216^{\circ} \mathrm{C}$, indicating a thermal transformation of 22 at this temperature. We are indebted to Prof. Dr. H. Butenschön, Technische Universität Hannover, for recording the DSC plot. 
Scheme 13
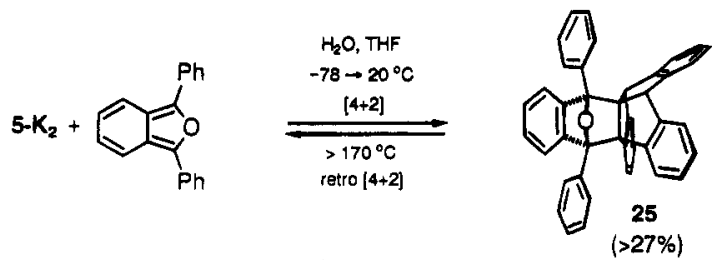

revealed a lengthening of the corresponding $\mathrm{C}(1)-\mathrm{C}(2)$ bond to $158.7 \pm 0.5 \mathrm{pm}$. As compared to usual $\mathrm{C}\left(\mathrm{sp}^{3}\right)-\mathrm{C}\left(\mathrm{sp}^{3}\right)$ single bonds, the lengthening effect is again ca. $4 \mathrm{pm}$.

Heating of dimer 22 with tetracyclone (Scheme 12) at 220 ${ }^{\circ} \mathrm{C}$ led to the adduct 24 after loss of $\mathrm{CO}$. It may be noted that this compound represents the first triquinacene bearing a 1,3cyclohexadiene unit fused to one of the central $\mathrm{C}-\mathrm{C}$ bonds. ${ }^{25}$

At low temperatures $\left(-78 \rightarrow+20^{\circ} \mathrm{C}\right)$, monomer $6 \mathrm{a}$ was also trapped directly with electron-rich dienes like 1,3-diphenylisobenzofuran. Best results were obtained by addition of water (as aqueous THF) to a stirred solution of dianion 5 and 3 equiv of diphenylisobenzofuran in THF at $-78^{\circ} \mathrm{C}$. After the mixture had been allowed to warm to room temperature, TLC analysis showed the Diels-Alder adduct $\mathbf{2 5}$ to be present as the major product and only a trace of dimer 22 . Nevertheless, only $27 \%$ of pure $\mathbf{2 5}$ was isolated, because separation from the remaining diphenylisobenzofuran was extremely difficult due to similar retention times. The Diels-Alder reaction between the intermediate 6a and diphenylisobenzofuran was also found to be reversible at higher temperatures (Scheme 13). Hence, the deepyellow color of the reagent was observed by heating 25 to ca. $170^{\circ} \mathrm{C}$, and a mixture of 25 and anthracene gave the anthracene adduct 23 when heated at $220^{\circ} \mathrm{C}$.

\section{Experimental Section}

General Remarks. 'H NMR: Bruker AM $250(250 \mathrm{MHz})$, WH $270(270 \mathrm{MHz})$, AM $300(300 \mathrm{MHz})$, WM $400(400 \mathrm{MHz})$, Varian VXR $500 \mathrm{~S}(500 \mathrm{MHz}) ; \delta(\mathrm{ppm})=0.00$ for tetramethylsilane, 1.93 for $\left[D_{2}\right]$ acetonitrile, 7.15 for $\left[D_{5}\right]$ benzene, 7.26 for chloroform, 5.35 for [D]dichloromethane, 3.22 for $\left[\mathrm{D}_{9}\right]$ dimethoxyethane (DME), 1.73 for $\left[\mathrm{D}_{7}\right] \mathrm{THF}$; characterization of signals, $\mathrm{s}=$ singlet, $\mathrm{br} \mathrm{s}=$ broad singlet, $\mathrm{d}=$ doublet, $\mathrm{t}=$ triplet, $\mathrm{q}=$ quartet, $\mathrm{m}=$ multiplet, $\mathrm{m}_{\mathrm{c}}=$ centrosymmetric multiplet, $\mathrm{dd}=$ doublet of doublets, $\mathrm{dt}=$ doublet of triplets. ${ }^{13} \mathrm{C}$ NMR: Bruker AM $250(62.9 \mathrm{MHz})$, WH $270(67.9 \mathrm{MHz})$, AM $300(75.5 \mathrm{MHz})$, WM $400(100.6 \mathrm{MHz})$, Varian VXR $500(125.7$ $\mathrm{MHz}) ; \delta(\mathrm{ppm})=0.0$ for tetramethylsilane, 1.3 for $\left[\mathrm{D}_{3}\right]$ acetonitrile, 128.0 for $\left[\mathrm{D}_{6}\right]$ benzene, 77.0 for $\mathrm{CDCl}_{3}, 53.5$ for $\left[\mathrm{D}_{2}\right]$ dichloromethane, 71.1 for $\left[\mathrm{D}_{10}\right]$ dimethoxyethane (DME), 67.4 for $\left[\mathrm{D}_{7}\right] \mathrm{THF}$; assignment generally based on spectra obtained using the DEPT technique (DEPT $=$ distortionless enhancement by polarization transfer). For DEPT spectra primary and tertiary carbons are designated as + and secondary carbons as -; missing DEPT signals are designated $\mathrm{C}_{9},{ }^{13} \mathrm{C}$ NMR spectra for mono- and dianions were obtained only for dianion $\mathbf{5 - K _ { 2 } /}$ $\mathbf{L i}_{\mathbf{2}}$ and monoanions $\mathbf{8 b}$ and $\mathbf{8 e}$; all other anions were not sufficiently soluble or abstracted deuterons too quickly from the solvent $\left[\mathrm{D}_{10}\right] \mathrm{DME}$ for being observed even at $-60^{\circ} \mathrm{C}$. IR: Bruker IFS 66 (FT-IR), PerkinElmer 125, 298, 399. MS: Varian MAT CH7, Finnigan MAT 95; HRMS were determined with a Varian MAT $311 \mathrm{~A}$, using preselected ion peak matching at $R \approx 10000$ to be within $\pm 2 \mathrm{ppm}$ of the exact mass. Because of the sensitivity of tribenzodihydroacepentalene derivatives $\mathbf{6 c}-\mathbf{f}$ toward light, moisture, and air, satisfactory elementary analyses could not be obtained in most cases. Column chromatography: silica gel 60 ( $70-230$ mesh, E. Merck, Darmstadt). Flash chromatography: silica gel, chromatography medium $60(20-45 \mu \mathrm{m}$, Amicon). Thin-layer chromatography (TLC): Alugram Sil G/UV 254 (Macherey-Nagel, Düren). Melting point (mp) determination: melting point apparatus of Wagner \& Munz; melting points are uncorrected. Elementary analyses: Mikroanalytisches Laboratorium, Institut für Organische Chemie der Georg-August-Universität Göttingen. Singlecrystal X-ray structure analyses: the diffraction data were recorded on a Stoe-Siemens four angle and solved by direct methods (SHELXTL program). ${ }^{46,47}$ Solvents used were dried by refluxing over sodium and distilled immediately before use. All reactions were carried out under an inert atmosphere in oven-dried glassware. All NMR samples of air sensitive materials were prepared in a glovebox under a nitrogen atmosphere, and the solvent was added at low temperature. The suspensions of all tribenzotriquinacene anions were directly transferred via a steel cannula from the reaction flask to a glass filter (P4) under an argon atmosphere, washed several times with dry $n$-hexane, and transferred into a Schlenk flask. Potassium tert-pentoxide was prepared according to Pearson's procedure. ${ }^{48}$ All tribenzotriquinacene substrates were obtained by published procedures. ${ }^{13-15,26}$

General Procedure for the Reaction of Tribenzotriquinacenes with Lochmann-Schlosser Base (GP1). To a stirred suspension of the respective tribenzotriquinacene $(0.30 \mathrm{mmol})$ in $3 \mathrm{~mL}$ of $n$-hexane were added dropwise at ambient temperature $n$-butyllithium $(0.76 \mathrm{~mL}$, $1.8 \mathrm{mmol}, 2.36 \mathrm{~N})$ in $n$-hexane and potassium tert-pentoxide $(1.0 \mathrm{~mL}$, $0.90 \mathrm{mmol}, 0.90 \mathrm{~N}$ ) in $n$-hexane. The reaction mixture turned red immediately and was stirred for an additional $36 \mathrm{~h}$ at ambient temperature and then for $36 \mathrm{~h}$ at $69^{\circ} \mathrm{C}$ in an oil bath. The suspension was filtered and the red residue washed three times with dry $n$-hexane $(5 \mathrm{~mL}$ each) under an argon atmosphere. The product was dried in vacuo (0.01 Torr) for $1 \mathrm{~h}$.

Potassium 1-Tribenzotriquinacenide (8a) and Dipotassium Tribenzacepentalenediide $\left(5-K_{2}\right)$ from $4 a$. The products $(133 \mathrm{mg})$ obtained from $4 \mathrm{a}(84 \mathrm{mg})$ according to GP1 were identified by their NMR data as a mixture of potassium 1-tribenzotriquinacenide $(\mathbf{8 a})$ and dipotassium tribenzacepentalenediide $\left(5-\mathbf{K}_{2}\right)$ in a ratio of $1: 2.3$ besides some aliphatic impurities: ${ }^{49}{ }^{1} \mathrm{H}$ NMR $\left(250 \mathrm{MHz},\left[\mathrm{D}_{10}\right] \mathrm{DME} / \mathrm{C}_{6} \mathrm{D}_{6}, 3: 1\right)$ (8a) $\delta 4.02[\mathrm{~d}, J=7.5 \mathrm{~Hz}, 2 \mathrm{H}, 4(7)-\mathrm{H}], 4.51(\mathrm{t}, J=7.5 \mathrm{~Hz}, 1 \mathrm{H}$, $10-\mathrm{H}), 5.83\left(\mathrm{t}, J=7.0 \mathrm{~Hz}, 2 \mathrm{H}, 5^{\prime}-\mathrm{H}\right), 6.11\left(\mathrm{~d}, J=7.5 \mathrm{~Hz}, 2 \mathrm{H}, 3^{\prime}-\mathrm{H}\right)$, $6.65\left(\mathrm{t}, J=7.5 \mathrm{~Hz}, 2 \mathrm{H}, 4^{\prime}-\mathrm{H}\right), 6.95-7.05\left[\mathrm{~m}, 4 \mathrm{H}, 6^{\prime}\left(4^{\prime \prime}, 5^{\prime \prime}\right)-\mathrm{H}\right], 7.23-$ $7.30\left[\mathrm{~m}, 2 \mathrm{H}, 3^{\prime \prime}\left(6^{\prime \prime}\right)-\mathrm{H}\right] ;\left(\mathbf{5}-\mathrm{K}_{2}\right) \delta 6.75\left[\mathrm{AA}^{\prime}\right.$ part, $\left.6 \mathrm{H}, 4^{\prime}\left(5^{\prime}\right)-\mathrm{H}\right], 7.80$ [XX' part, $\left.6 \mathrm{H}, 3^{\prime}\left(6^{\prime}\right)-\mathrm{H}\right]$; for ${ }^{13} \mathrm{C}$ NMR see selective preparation of $\mathbf{5 - K _ { 2 }}$.

Potassium 10-Methyl-1-tribenzotriquinacenide (8b), Dipotassium 10-Methyl-1,4-tribenzotriquinacenediide (10b), and Dipotassium Tribenzacepentalenediide $\left(5-\mathbf{K}_{2}\right)$ from $4 \mathrm{~b}$. The products $(99 \mathrm{mg})$ obtained from $4 \mathrm{~b}(88 \mathrm{mg})$ according to GP1 were identified by their NMR data as a mixture of potassium 10-methyl-1-tribenzotriquinacenide (8b), dipotassium 10-methyl-1,4-tribenzotriquinacenediide (10b), and dipotassium 4,7-tribenzacepentalenediide $\left(\mathbf{5}-\mathbf{K}_{2}\right)$ in a ratio of 2.7:2.3:1 besides some aliphatic impurities: ${ }^{49}{ }^{1} \mathrm{H}$ NMR $\left(250 \mathrm{MHz},\left[\mathrm{D}_{10}\right] \mathrm{DME} /\right.$ $\left.\mathrm{C}_{6} \mathrm{D}_{6}, 3: 1\right)(8 \mathrm{~b}) \delta 1.10\left(\mathrm{~s}, 3 \mathrm{H}, \mathrm{CH}_{3}\right), 3.80[\mathrm{~s}, 2 \mathrm{H}, 4(7)-\mathrm{H}], 5.82(\mathrm{dt}$, $\left.J=7.0,1.0 \mathrm{~Hz}, 2 \mathrm{H}, 5^{\prime}-\mathrm{H}\right), 6.16$ (dd, $\left.J=7.5,1.0 \mathrm{~Hz}, 2 \mathrm{H}, 3^{\prime}-\mathrm{H}\right), 6.65$ $\left(\mathrm{dt}, J=7.5,1.0 \mathrm{~Hz}, 2 \mathrm{H}, 4^{\prime}-\mathrm{H}\right), 7.01\left(\mathrm{~d}, J=7.0 \mathrm{~Hz}, 2 \mathrm{H}, 6^{\prime}-\mathrm{H}\right), 7.02$ $\left[\mathrm{m}_{\mathrm{c}}, 2 \mathrm{H}, 4^{\prime \prime}\left(5^{\prime \prime}\right)-\mathrm{H}\right], 7.27\left[\mathrm{~m}_{\mathrm{c}}, 2 \mathrm{H}, 3^{\prime \prime}\left(6^{\prime \prime}\right)-\mathrm{H}\right]$; for ${ }^{13} \mathrm{C}$ NMR see selective preparation of $\mathbf{8 b} ;(\mathbf{1 0 b}) \delta 1.08\left(\mathrm{~s}, 3 \mathrm{H}, \mathrm{CH}_{3}\right), 3.50(\mathrm{~s}, 1 \mathrm{H}$, $7-\mathrm{H}), 5.76\left(\mathrm{dt}, J=7.0,1.0 \mathrm{~Hz}, 2 \mathrm{H}, 5^{\prime}-\mathrm{H}\right), 6.12(\mathrm{dd}, J=7.5,1.0 \mathrm{~Hz}$ $\left.2 \mathrm{H}, 3^{\prime}-\mathrm{H}\right), 6.30$ [AA' part, $2 \mathrm{H}, 4^{\prime \prime}\left(5^{\prime \prime}\right)-\mathrm{H}$ ], 6.48 [BB' part, $2 \mathrm{H}, 3^{\prime \prime}\left(6^{\prime \prime}\right)-$ $\mathrm{H}], 6.57\left(\mathrm{dt}, J=7.5,1.0 \mathrm{~Hz}, 2 \mathrm{H}, 4^{\prime}-\mathrm{H}\right), 6.92(\mathrm{~d}, J=7.0 \mathrm{~Hz}, 2 \mathrm{H}$, $\left.6^{\prime}-\mathrm{H}\right)$.

Potassium 10-Ethyl-1-tribenzotriquinacenide (8c), Dipotassium 10-Ethyl-1,4-tribenzotriquinacenediide (10c), and Dipotassium Tribenzacepentalenediide $\left(5-K_{2}\right)$ from $4 c$. The products $(137 \mathrm{mg})$ obtained from $4 \mathrm{c}(92 \mathrm{mg}$ ) according to GP1 were identified by their NMR data as a mixture of potassium 10-ethyl-1-tribenzotriquinacenide (8c), dipotassium 10-ethyl-1,4-tribenzotriquinacenediide (10c), and dipotassium tribenzacepentalenediide $\left(\mathbf{5}-\mathbf{K}_{\mathbf{2}}\right)$ in a ratio of 9.3:7.2:1 besides some aliphatic impurities:49 ${ }^{1} \mathrm{H}$ NMR $\left(250 \mathrm{MHz},\left[\mathrm{D}_{10}\right] \mathrm{DME} /\right.$ $\left.\mathrm{C}_{6} \mathrm{D}_{6}, 3: 1\right)(8 \mathrm{c}) \delta 1.04\left(\mathrm{t}, J=7.5 \mathrm{~Hz}, 3 \mathrm{H}, \mathrm{CH}_{3}\right), 1.69(\mathrm{q}, J=7.5 \mathrm{~Hz}$, $\left.2 \mathrm{H}, \mathrm{CH}_{2}\right), 3.80[\mathrm{~s}, 2 \mathrm{H}, 4(7)-\mathrm{H}], 5.82\left(\mathrm{dt}, J=7.0,1.0 \mathrm{~Hz}, 2 \mathrm{H}, 5^{\prime}-\mathrm{H}\right)$, $6.16\left(\mathrm{dd}, J=7.5,1.0 \mathrm{~Hz}, 2 \mathrm{H}, 3^{\prime}-\mathrm{H}\right), 6.65(\mathrm{dt}, J=7.5,1.0 \mathrm{~Hz}, 2 \mathrm{H}$, $\left.4^{\prime}-\mathrm{H}\right), 7.01\left[\mathrm{~m}_{\mathrm{c}}, 4 \mathrm{H}, 6^{\prime}\left(4^{\prime \prime}, 5^{\prime \prime}\right)-\mathrm{H}\right], 7.27\left[\mathrm{~m}_{\mathrm{c}}, 2 \mathrm{H}, 3^{\prime \prime}\left(6^{\prime \prime}\right)-\mathrm{H}\right] ;(10 \mathrm{c}) \delta$ 1.06 (t, $\left.J=7.5 \mathrm{~Hz}, 3 \mathrm{H}, \mathrm{CH}_{3}\right), 1.68\left(\mathrm{q}, J=7.5 \mathrm{~Hz}, 2 \mathrm{H}, \mathrm{CH}_{2}\right), 3.50$ $(\mathrm{s}, 1 \mathrm{H}, 7-\mathrm{H}), 5.75\left(\mathrm{dt}, J=7.0,1.0 \mathrm{~Hz}, 2 \mathrm{H}, 5^{\prime}-\mathrm{H}\right), 6.11(\mathrm{dd}, J=7.5$, $\left.1.0 \mathrm{~Hz}, 2 \mathrm{H}, 3^{\prime}-\mathrm{H}\right), 6.27$ [AA' part, $\left.2 \mathrm{H}, 4^{\prime \prime}\left(5^{\prime \prime}\right)-\mathrm{H}\right], 6.44$ [BB' part, 2 $\left.\mathrm{H}, 3^{\prime \prime}\left(6^{\prime \prime}\right)-\mathrm{H}\right), 6.56\left(\mathrm{dt}, J=7.5,1.0 \mathrm{~Hz}, 2 \mathrm{H}, 4^{\prime}-\mathrm{H}\right), 6.92$ (d, $J=7.0$ $\left.\mathrm{Hz}, 2 \mathrm{H}, 6^{\prime}-\mathrm{H}\right)$.

(46) Sheldrick, G. M. Acta Crytallogr., Sect. A 1990, 46, 467

(47) Sheldrick, G. M. SHELXL-93, program for crystal structure refinement, University of Göttingen, 1993.

(48) Pearson, D. E.; Keaton, O. D. J. Org. Chem. 1963, 28, 1557-1558.

(49) All prepared potassium carbanionic salts contain lithium tertpentoxides in an aggregated form ${ }^{8}$ due to the large excess of $\mathrm{LSB}^{7}$ used. Therefore, the yields were not calculated; in these cases the yields of the trapping reactions are representative. 
Potassium 10-Benzyl-1-tribenzotriquinacenide (8d), Dipotassium 10-Benzyl-1,4-tribenzotriquinacenediide (10d), and Dipotassium Tribenzacepentalenediide $\left(5-K_{2}\right)$ from $4 d$. The products $(169 \mathrm{mg})$ obtained from $4 \mathrm{~d}(111 \mathrm{mg}$ ) according to GP1 were identified by their NMR data as a mixture of potassium 10-benzyl-1-tribenzotriquinacenide (8d), dipotassium 10-benzyl-1,4-tribenzotriquinacenediide (10d), and dipotassium tribenzacepentalenediide $\left(\mathbf{5}-\mathbf{K}_{2}\right)$ in a ratio of $1.1: 1: 1$ besides some aliphatic impurities: ${ }^{49}{ }^{1} \mathrm{H}$ NMR $\left(250 \mathrm{MHz},\left[\mathrm{D}_{10}\right] \mathrm{DME} / \mathrm{C}_{6} \mathrm{D}_{6}, 3: 1\right)$ (8d) $\delta 2.92\left(\mathrm{~s}, 2 \mathrm{H}, \mathrm{CH}_{2}\right), 4.00[\mathrm{~s}, 2 \mathrm{H}, 4(7)-\mathrm{H}], 5.88(\mathrm{dt}, J=7.0,1.0$ $\left.\mathrm{Hz}, 2 \mathrm{H}, 5^{\prime}-\mathrm{H}\right), 6.19$ (dd, $\left.J=7.5,1.0 \mathrm{~Hz}, 2 \mathrm{H}, 3^{\prime}-\mathrm{H}\right), 6.71(\mathrm{dt}, J=7.5$, $\left.1.0 \mathrm{~Hz}, 2 \mathrm{H}, 4^{\prime}-\mathrm{H}\right), 6.95\left[\mathrm{~m}_{\mathrm{c}}, 2 \mathrm{H}, 4^{\prime \prime}\left(5^{\prime \prime}\right)-\mathrm{H}\right], 7.00-7.22\left[\mathrm{~m}, 7 \mathrm{H}, 6^{\prime}-\right.$ (benzyl)-H], 7.23-7.35 [m, $\left.2 \mathrm{H}, 3^{\prime \prime}\left(6^{\prime \prime}\right)-\mathrm{H}\right]$; (10d) $\delta 2.68\left(\mathrm{~s}, 2 \mathrm{H}, \mathrm{CH}_{2}\right.$ ), $3.82(\mathrm{~s}, 1 \mathrm{H}, 7-\mathrm{H}), 5.65\left(\mathrm{~m}_{\mathrm{c}}, 2 \mathrm{H}, 5^{\prime}-\mathrm{H}\right), 6.10\left(\mathrm{~m}_{\mathrm{c}}, 2 \mathrm{H}, 3^{\prime}-\mathrm{H}\right), 6.25-$ $6.45\left[\mathrm{~m}, 4 \mathrm{H}, 3^{\prime \prime}\left(4^{\prime \prime}, 5^{\prime \prime}, 6^{\prime \prime}\right)-\mathrm{H}\right], 6.56\left(\mathrm{~m}_{\mathrm{c}}, 2 \mathrm{H}, 4^{\prime}-\mathrm{H}\right), 6.95\left[\mathrm{~m}_{\mathrm{c}}, 7 \mathrm{H}\right.$, $6^{\prime}$ (benzyl)-H]

Potassium 10-Benzhydryl-1-tribenzotriquinacenide (8e) and Dipotassium Tribenzacepentalenediide $\left(5-\mathrm{K}_{2}\right)$ from $4 e$. The products (195 mg) obtained from 4 e (134 mg) according to GP1 were identified by their NMR data as a mixture of potassium 10-benzhydryl-1tribenzotriquinacenide (8e) and dipotassium tribenzacepentalenediide $\left(5-\mathbf{K}_{2}\right)$ in a ratio of $5: 1$ besides some aliphatic impurities: ${ }^{49}{ }^{1} \mathrm{H}$ NMR $\left(250 \mathrm{MHz},\left[\mathrm{D}_{10}\right] \mathrm{DME} / \mathrm{C}_{6} \mathrm{D}_{6}, 3: 1,{ }^{1} \mathrm{H}-{ }^{\prime} \mathrm{H}\right.$ COSY and long-range ${ }^{1} \mathrm{H}-$ ${ }^{i} \mathrm{H}$ COSY) (8e) $\delta 4.20[\mathrm{~s}, 2 \mathrm{H}, 4(7)-\mathrm{H}], 4.29(\mathrm{~s}, 1 \mathrm{H}, \mathrm{CH}), 5.73(\mathrm{dt}, J$ $\left.=7.0,1.0 \mathrm{~Hz}, 2 \mathrm{H}, 5^{\prime}-\mathrm{H}\right), 6.15\left(\mathrm{dd}, J=7.5,1.0 \mathrm{~Hz}, 2 \mathrm{H}, 3^{\prime}-\mathrm{H}\right), 6.58$ (dt, $\left.J=7.5,1.0 \mathrm{~Hz}, 2 \mathrm{H}, 4^{\prime}-\mathrm{H}\right), 6.66-6.78\left[\mathrm{~m}, 2 \mathrm{H}, 4^{\prime \prime}\left(5^{\prime \prime}\right)-\mathrm{H}\right], 6.79$ (d, $\left.J=7.0 \mathrm{~Hz}, 2 \mathrm{H}, 6^{\prime}-\mathrm{H}\right), 6.90-7.05(\mathrm{~m}, 6 \mathrm{H}$, benzhydryl-H), $7.20-$ $7.33\left[\mathrm{~m}_{\mathrm{c}}, 2 \mathrm{H}, 3^{\prime \prime}\left(6^{\prime \prime}\right)-\mathrm{H}\right], 7.41$ (d, $4 \mathrm{H}$, benzhydryl-H); ${ }^{13} \mathrm{C}$ NMR $(125.7$ $\mathrm{MHz},\left[\mathrm{D}_{10}\right] \mathrm{DME}, \mathrm{DEPT}$ and $\mathrm{C}-\mathrm{H}$ correlation) (8e) $\delta 57.8[+, \mathrm{C}-4(7)]$, $59.6(+, \mathrm{CH}), 70.0\left(\mathrm{C}_{\mathrm{q}}, \mathrm{C}-10\right), 94.5\left(\mathrm{C}_{4}, \mathrm{C}-1\right), 107.3\left(+, \mathrm{C}-5^{\prime}\right), 108.9$ $\left(+, \mathrm{C}-3^{\prime}\right), 122.0\left(+, \mathrm{C}-6^{\prime}\right), 124.5\left[+, \mathrm{C}-3^{\prime \prime}\left(6^{\prime \prime}\right)\right], 125.3\left[+, \mathrm{C}-4^{\prime \prime}\left(5^{\prime \prime}\right)\right]$, 126.3 (+, C-benzhydryl), 127.6 (+, C-benzhydryl), $128.0\left(+, \mathrm{C}-4^{\prime}\right)$, 130.6 (+, C-benzhydryl), $146.1\left[\mathrm{C}_{q}, \mathrm{C}-2(9)\right], 147.1\left[\mathrm{C}_{\mathrm{q}}, \mathrm{C}-3(8)\right], 148.2$ $\left(\mathrm{C}_{\mathrm{q}}, \mathrm{C}\right.$-benzhydryl), $150.5\left[\mathrm{C}_{\mathrm{q}}, \mathrm{C}-5(6)\right]$.

Selective Preparation of Potassium 10-Methyl-1-tribenzotriquinacenide (8b). To a stirred suspension of 10 -methyltribenzotriquinacene (4b) (161 mg, $0.54 \mathrm{mmol})$ in $7 \mathrm{~mL}$ of $n$-hexane was added dropwise at ambient temperature $n$-butyllithium $(0.67 \mathrm{~mL}, 1.63 \mathrm{mmol}, 2.36 \mathrm{~N})$ in $n$-hexane. Then potassium tert-pentoxide $(0.91 \mathrm{~mL}, 0.68 \mathrm{mmol}, 0.75$ $\mathrm{N})$ in $n$-hexane was injected over a period of $16 \mathrm{~h}$ at $40^{\circ} \mathrm{C}$. The reaction mixture was filtered and the red residue washed three times with dry hexane $(10 \mathrm{~mL}$ each) under an argon atmosphere. Some material was lost with the filtrate, because the suspension was too fine for the glass filter (P4). The product was dried in vacuo (0.01 Torr) for $1 \mathrm{~h}$ to yield $136 \mathrm{mg}(76 \%)$ of potassium 10-methyl-1-tribenzotriquinacenide (8b): ${ }^{1} \mathrm{H}$ NMR $\left(500 \mathrm{MHz},\left[\mathrm{D}_{10}\right] \mathrm{DME},-60{ }^{\circ} \mathrm{C},{ }^{1} \mathrm{H}-{ }^{-1} \mathrm{H}\right.$ $\operatorname{COSY}) \delta 1.14\left(\mathrm{~s}, 3 \mathrm{H}, \mathrm{CH}_{3}\right), 3.47[\mathrm{~s}, 2 \mathrm{H}, 4(7)-\mathrm{H}], 5.64(\mathrm{dt}, J=7.0$, $\left.1.0 \mathrm{~Hz}, 2 \mathrm{H}, 5^{\prime}-\mathrm{H}\right), 5.93\left(\mathrm{dd}, J=7.5,1.0 \mathrm{~Hz}, 2 \mathrm{H}, 3^{\prime}-\mathrm{H}\right), 6.48(\mathrm{dt}, J$ $\left.=7.5,1.0 \mathrm{~Hz}, 2 \mathrm{H}, 4^{\prime}-\mathrm{H}\right), 6.86\left(\mathrm{dd}, J=7.0,1.0 \mathrm{~Hz}, 2 \mathrm{H}, 6^{\prime}-\mathrm{H}\right), 6.93$ [AA' part, $2 \mathrm{H}, 4^{\prime \prime}\left(5^{\prime \prime}\right)-\mathrm{H}$ ], 7.11 [BB' part, $\left.2 \mathrm{H}, 3^{\prime \prime}\left(6^{\prime \prime}\right)-\mathrm{H}\right] ;{ }^{13} \mathrm{C}$ NMR $\left(125.7 \mathrm{MHz},\left[\mathrm{D}_{10}\right] \mathrm{DME},-60^{\circ} \mathrm{C}, \mathrm{DEPT}, \mathrm{C}-\mathrm{H}\right.$ correlation) $\delta 25.1(+$, $\left.\mathrm{CH}_{3}\right), 59.8[+, \mathrm{C}-4(7)], 62.3\left(\mathrm{C}_{\mathrm{q}}, \mathrm{C}-10\right), 97.6\left(\mathrm{C}_{\mathrm{q}}, \mathrm{C}-1\right), 106.8\left(+, \mathrm{C}-5^{\prime}\right)$, $109.0\left(+, C-3^{\prime}\right), 122.6\left(+, C-6^{\prime}\right), 124.6\left[+, C-3^{\prime \prime}\left(6^{\prime \prime}\right)\right], 126.0\left[+, C-4^{\prime \prime}-\right.$ $\left.\left(5^{\prime \prime}\right)\right], 128.0\left(+, C^{\prime}\right), 137.4\left[C_{q}, C-2(9)\right], 146.1\left[C_{q}, C-3(8)\right], 150.7$ $\left[\mathrm{C}_{\mathrm{q}}, \mathrm{C}-5(6)\right]$

General Procedure for the Reaction of Potassium 10-Methyl-1tribenzotriquinacenide (8b) with Electrophiles (GP2). To a solution of the respective electrophile $(1.0 \mathrm{mmol}, 3.3$ equiv) in $5 \mathrm{~mL}$ of THF was added dropwise at $-78^{\circ} \mathrm{C}$ a suspension of $100 \mathrm{mg}(0.30 \mathrm{mmol})$ of potassium 10-methyl-1-tribenzotriquinacenide $(\mathbf{8 b})$ in $3 \mathrm{~mL}$ of $n$-hexane; the red mixture was stirred for $1 \mathrm{~h}$ at $-78^{\circ} \mathrm{C}$ and then allowed to warm slowly to room temperature, while the color changed to pale yellow. The reaction mixture was diluted with $30 \mathrm{~mL}$ of pentane and washed three times with saturated ammonium chloride solution (10 $\mathrm{mL}$ each). The organic layer was dried with $\mathrm{MgSO}_{4}$, and the solvent was removed in vacuo. The crude product was purified by flash column chromatography (eluent $=$ petroleum ether/ethyl acetate, $100: 1)$ and recrystallization from hexane/ethyl acetate.

1,10-Dimethyltribenzotriquinacene (11a). The product obtained from $\mathbf{8 b}$ and dimethyl sulfate $(390 \mu \mathrm{L})$ according to GP2 yielded 48 $\mathrm{mg}(52 \%)$ of 11a as colorless needles: $\mathrm{mp} 173^{\circ} \mathrm{C}$; IR (KBr) $v\left(\mathrm{~cm}^{-1}\right)$ $3070,3020,2980,2930,2880,1480,1460,1030,770,755,735 ;{ }^{1} \mathrm{H}$ NMR $\left(250 \mathrm{MHz}, \mathrm{CDCl}_{3}\right) \delta 1.60\left(\mathrm{~s}, 3 \mathrm{H}, 1-\mathrm{CH}_{3}\right), 1.72(\mathrm{~s}, 3 \mathrm{H}, 10-$ $\left.\mathrm{CH}_{3}\right), 4.48[\mathrm{~s}, 2 \mathrm{H}, 4(7)-\mathrm{H}], 7.13-7.27\left[\mathrm{~m}, 6 \mathrm{H}, 4^{\prime}\left(5^{\prime}, 4^{\prime \prime}, 5^{\prime \prime}\right)-\mathrm{H}\right], 7.38-$ $7.54\left[\mathrm{~m}, 6 \mathrm{H}, 3^{\prime}\left(6^{\prime}, 3^{\prime \prime}, 6^{\prime \prime}\right)-\mathrm{H}\right] ;{ }^{13} \mathrm{C}$ NMR $\left(62.9 \mathrm{MHz}, \mathrm{CDCl}_{3}, \mathrm{DEPT}\right) \delta$ $24.2\left(+, 1-\mathrm{CH}_{3}\right), 24.3\left(+, 10-\mathrm{CH}_{3}\right), 61.7\left(\mathrm{C}_{9}, \mathrm{C}-1\right), 63.6\left(\mathrm{C}_{\mathrm{q}}, \mathrm{C}-10\right)$, $64.5[+, \mathrm{C}-4(7)], 123.3,124.1,124.5\left[+, \mathrm{C}-3^{\prime}\left(6^{\prime}, 3^{\prime \prime}, 6^{\prime \prime}\right], 127.4,127.5\right.$, $127.6\left[+, \mathrm{C}^{\prime} 4^{\prime}\left(5^{\prime}, 4^{\prime \prime}, 5^{\prime \prime}\right)\right], 143.6,145.4,150.8$ [C $\left.\mathrm{q}, \mathrm{C}-2(3,5,6,8,9)\right]$; MS $(\mathrm{EI}, 70 \mathrm{eV}) \mathrm{m} / \mathrm{z}$ (relative intensity) $=308\left(56, \mathrm{M}^{+}\right), 293(100$, [M $\left.\left.\mathrm{CH}_{3}\right]^{+}\right), 278$ (19), 265 (8), 215 (23), 143 (21), 111 (13); correct HRMS for $\mathrm{C}_{24} \mathrm{H}_{20}$, calcd 308.1565 .

1-Ethyl-10-methyltribenzotriquinacene (11b). The product obtained from $8 \mathbf{b}$ and diethyl sulfate $(131 \mu \mathrm{L})$ according to GP2 yielded $65 \mathrm{mg}(66 \%)$ of $11 \mathrm{~b}$ as colorless crystals: $\mathrm{mp} 146{ }^{\circ} \mathrm{C}$; $\mathrm{IR}(\mathrm{KBr}) v$ $\left(\mathrm{cm}^{-1}\right)$ 3060, 3020, 2960, 2930, 2910, 2870,1600,1580, 1475, 1455, $1390,1205,1150,1025,775,755,740,725,710,660 ;{ }^{\prime} \mathrm{H}$ NMR $(250$ $\left.\mathrm{MHz}, \mathrm{CDCl}_{3}\right) \delta 0.83\left(\mathrm{t}, J=8.0 \mathrm{~Hz}, 3 \mathrm{H}, \mathrm{CH}_{2} \mathrm{CH}_{3}\right), 1.68(\mathrm{~s}, 3 \mathrm{H}$, $\left.10-\mathrm{CH}_{3}\right), 2.30\left(\mathrm{q}, J=8.0 \mathrm{~Hz}, 2 \mathrm{H}, \mathrm{CH}_{2} \mathrm{CH}_{3}\right), 4.42[\mathrm{~s}, 2 \mathrm{H}, 4(7)-\mathrm{H}]$, $7.07-7.24\left[\mathrm{~m}, 6 \mathrm{H}, 4^{\prime}\left(5^{\prime}, 4^{\prime \prime}, 5^{\prime \prime}\right)-\mathrm{H}\right], 7.27-7.40\left[\mathrm{~m}, 4 \mathrm{H}, 3^{\prime}\left(6^{\prime}\right)-\mathrm{H}\right]$, $7.41-7.49\left[\mathrm{~m}, 2 \mathrm{H}, 3^{\prime \prime}\left(6^{\prime \prime}\right)-\mathrm{H}\right] ;{ }^{13} \mathrm{C}$ NMR $\left(62.9 \mathrm{MHz}, \mathrm{CDCl}_{3}\right.$, DEPT) $\delta 11.7\left(+, \mathrm{CH}_{2} \mathrm{CH}_{3}\right), 24.3\left(+, 10-\mathrm{CH}_{3}\right), 29.3\left(-, \mathrm{CH}_{2} \mathrm{CH}_{3}\right), 64.0\left(\mathrm{C}_{\mathrm{q}}\right.$, C-10), 65.1 [+, C-4(7)], $65.9\left(\mathrm{C}_{\mathrm{q}}, \mathrm{C}-1\right), 123.8,124.0,124.8[+$, C-3' $\left.\left(6^{\prime}, 3^{\prime \prime}, 6^{\prime \prime}\right)\right], 127.3,127.4,127.6\left[+, \mathrm{C}-4^{\prime}\left(5^{\prime}, 4^{\prime \prime}, 5^{\prime \prime}\right)\right], 144.1,145.4$, $149.5\left[\mathrm{C}_{\mathrm{q}}, \mathrm{C}-2(3,5,6,8,9)\right]$; MS (EI, $\left.70 \mathrm{eV}\right) \mathrm{m} / \mathrm{z}$ (relative intensity) $=$ $323(2), 322\left(11, \mathrm{M}^{+}\right), 293\left(64,[\mathrm{M}-\mathrm{Et}]^{+}\right), 278(7), 215(9), 78(100)$. Anal. Calcd for $\mathrm{C}_{25} \mathrm{H}_{22}$ : C, $93.11 ; \mathrm{H}, 6.89$. Found: $\mathrm{C}, 93.12 ; \mathrm{H}, 6.93$.

1-(n-Hexyl)-10-methyltribenzotriquinacene (11c). The product obtained from $8 \mathrm{~b}$ and $n$-hexyl bromide $(140 \mu \mathrm{L})$ according to GP2 yielded $74 \mathrm{mg}(65 \%)$ of $11 \mathrm{c}$ as a colorless oil: IR (film) $\nu\left(\mathrm{cm}^{-1}\right)$ $3050,3010,2900,2850,1580,1460,1370,1150,755,740,660 ;{ }^{1} \mathrm{H}$ NMR $\left(250 \mathrm{MHz}, \mathrm{CDCl}_{3}\right) \delta 0.85\left(\mathrm{t}, J=8.0 \mathrm{~Hz}, 3 \mathrm{H}\right.$, hexyl- $\left.\mathrm{CH}_{3}\right), 1.05-$ $1.40\left(\mathrm{~m}, 8 \mathrm{H}\right.$, hexyl- $\left.\mathrm{CH}_{2}\right), 1.66\left(\mathrm{~s}, 3 \mathrm{H}, 10-\mathrm{CH}_{3}\right), 2.14-2.33(\mathrm{~m}, 2 \mathrm{H}$, $\left.1-\mathrm{CH}_{2}\right), 4.43$ [s, $\left.2 \mathrm{H}, 4(7)-\mathrm{H}\right], 7.07-7.24\left[\mathrm{~m}, 6 \mathrm{H}, 4^{\prime}\left(5^{\prime}, 4^{\prime \prime}, 5^{\prime \prime}\right)-\mathrm{H}\right]$, 7.26-7.40 [m, $\left.4 \mathrm{H}, 3^{\prime}\left(6^{\prime}\right)-\mathrm{H}\right], 7.41-7.49\left[\mathrm{~m}, 2 \mathrm{H}, 3^{\prime \prime}\left(6^{\prime \prime}\right)-\mathrm{H}\right] ;{ }^{13} \mathrm{C}$ NMR $\left(62.9 \mathrm{MHz}, \mathrm{CDCl}_{3}, \mathrm{DEPT}\right) \delta 14.1\left(+\right.$, hexyl- $\left.-\mathrm{CH}_{3}\right), 22.8(-$, hexyl$\left.\mathrm{CH}_{2}\right), 24.5\left(+, 10-\mathrm{CH}_{3}\right), 27.1,30.4,31.8\left(-\right.$, hexyl- $\left.\mathrm{CH}_{2}\right), 37.2(-$, $\left.1-\mathrm{CH}_{2}\right), 64.1\left(\mathrm{C}_{\mathrm{q}}, \mathrm{C}-10\right), 65.0[+, \mathrm{C}-4(7)], 65.5\left(\mathrm{C}_{\mathrm{q}}, \mathrm{C}-1\right), 123.7,124.0$, $124.5\left[+, \mathrm{C}-3^{\prime}\left(6^{\prime}, 3^{\prime \prime}, 6^{\prime \prime}\right)\right], 127.2,127.4,127.6\left[+, \mathrm{C}-4^{\prime}\left(5^{\prime}, 4^{\prime \prime}, 5^{\prime \prime}\right)\right], 144.0$, $145.4,149.7\left[\mathrm{C}_{\mathrm{q}}, \mathrm{C}-2(3,5,6,8,9)\right]$; MS (EI, $70 \mathrm{eV}$ ) $\mathrm{m} / \mathrm{z}$ (relative intensity) $=379(2), 378\left(6, \mathrm{M}^{+}\right), 294(21), 293\left(59,[\mathrm{M}-\text { hexyl }]^{+}\right), 278(8)$, 215 (9), 91 (15), 69 (41), 56 (100); correct HRMS for $\mathrm{C}_{29} \mathrm{H}_{30}$, calcd 378.2347 .

10-Methyl-1-(trimethylsilyl)tribenzotriquinacene (11d). The product obtained from $8 \mathbf{b}$ and trimethylsilyl chloride $(130 \mu \mathrm{L})$ according to $\mathrm{GP} 2$ yielded $98 \mathrm{mg}(89 \%)$ of $11 \mathrm{~d}$ as colorless crystals: $\mathrm{mp} 193{ }^{\circ} \mathrm{C}$; IR (KBr) $v\left(\mathrm{~cm}^{-1}\right) 3060,3020,2960,1600,1490,1480,1460,1250$, $1030,840,750,740$; ' $\mathrm{H}$ NMR $\left(250 \mathrm{MHz}, \mathrm{CDCl}_{3}\right) \delta 0.25(\mathrm{~s}, 9 \mathrm{H}$, $\left.\mathrm{SiMe}_{3}\right), 1.82$ (s, $\left.3 \mathrm{H}, 10-\mathrm{CH}_{3}\right), 4.44$ [s, $\left.2 \mathrm{H}, 4(7)-\mathrm{H}\right], 7.07-7.26[\mathrm{~m}, 6$ $\left.\mathrm{H}, 4^{\prime}\left(5^{\prime}, 4^{\prime \prime}, 5^{\prime \prime}\right)-\mathrm{H}\right], 7.35-7.52\left[\mathrm{~m}, 6 \mathrm{H}, 3^{\prime}\left(6^{\prime}, 3^{\prime \prime}, 6^{\prime \prime}\right)-\mathrm{H}\right] ;{ }^{13} \mathrm{C}$ NMR $(62.9$ $\left.\mathrm{MHz}, \mathrm{CDCl}_{3}, \mathrm{DEPT}\right) \delta 1.0\left(+, \mathrm{SiMe}_{3}\right), 28.1\left(+, 10-\mathrm{CH}_{3}\right), 59.6\left(\mathrm{C}_{\mathrm{q}}\right.$, $\mathrm{C}-1), 65.2\left(\mathrm{C}_{4}, \mathrm{C}-10\right), 66.0[+, \mathrm{C}-4(7)], 124.4,124.5,124.7[+$, $\left.\mathrm{C}-3^{\prime}\left(6^{\prime}, 3^{\prime \prime}, 6^{\prime \prime}\right)\right], 126.6,127.4,127.8\left[+, \mathrm{C}-4^{\prime}\left(5^{\prime}, 4^{\prime \prime}, 5^{\prime \prime}\right)\right], 144.9,146.0$, $149.5\left[\mathrm{C}_{\mathrm{q}}, \mathrm{C}-2(3,5,6,8,9)\right]$; $\mathrm{MS}(\mathrm{EI}, 70 \mathrm{eV}) \mathrm{m} / \mathrm{z}$ (relative intensity) $=$ $367(11), 366\left(44, \mathrm{M}^{+}\right), 351\left(7,\left[\mathrm{M}-\mathrm{CH}_{3}\right]^{+}\right), 293(100,[\mathrm{M}-$ $\left.\left.\mathrm{SiMe}_{3}\right]^{+}\right), 278(10), 215(12), 139(6), 73(45)$; correct HRMS for $\mathrm{C}_{26} \mathrm{H}_{26} \mathrm{Si}$, calcd 366.1804 .

Reaction of 1,10-Disubstituted Tribenzotriquinacenes with Lochmann-Schlosser Base. Potassium Indeno[1,10- $a]-4$-tribenzotriquinacenide (13) and Dipotassium Indeno[1,10-a]-4,11-tribenzotriquinacenediide (14). To a stirred suspension of indeno[1,10-a]tribenzotriquinacene (12; $37 \mathrm{mg}, 0.10 \mathrm{mmol}$ ) in $2 \mathrm{~mL}$ of $n$-hexane were added dropwise at ambient temperature $n$-butyilithium $(340 \mu \mathrm{L}, 0.80$ mmol, $2.36 \mathrm{~N})$ in $n$-hexane and potassium tert-pentoxide $(510 \mu \mathrm{L}, 0.40$ mmol, $0.78 \mathrm{~N}$ ) in $n$-hexane. The reaction mixture immediately turned red and was stirred for $24 \mathrm{~h}$ at ambient temperature and then for $48 \mathrm{~h}$ at $69^{\circ} \mathrm{C}$ in an oil bath. The suspension was filtered and the red residue washed three times with dry $n$-hexane $(3 \mathrm{~mL}$ each) under an argon atmosphere and then dried in vacuo (0.01 Torr) for $1 \mathrm{~h}$. The product (48 $\mathrm{mg}$ ) was identified by its ${ }^{1} \mathrm{H}$ NMR spectrum as a mixture of potassium indeno[1,10-a]-4-tribenzotriquinacenide (13) and dipotassium indeno $[1,10-a]-4,11$-tribenzotriquinacenediide $(14)$ in a ratio of $1: 1$ besides some aliphatic impurities: ${ }^{49}{ }^{1} \mathrm{H}$ NMR $\left(500 \mathrm{MHz},\left[\mathrm{D}_{10}\right] \mathrm{DME} /\right.$ $\mathrm{C}_{6} \mathrm{D}_{6}, 3: 1,{ }^{1} \mathrm{H}-{ }^{\prime} \mathrm{H}$ COSY and long-range $\left.{ }^{1} \mathrm{H}^{-1} \mathrm{H} \mathrm{COSY}\right)(13) \delta 3.05$ $\left(\mathrm{d}, J=16.0 \mathrm{~Hz}, 1 \mathrm{H}, 11-\mathrm{H}_{\mathrm{a}}\right), 3.39\left(\mathrm{~d}, J=16.0 \mathrm{~Hz}, 1 \mathrm{H}, 11-\mathrm{H}_{\mathrm{b}}\right), 3.87$ $(\mathrm{s}, 1 \mathrm{H}, 7 \cdot \mathrm{H}), 5.84\left(\mathrm{dt}, J=7.0,1.0 \mathrm{~Hz}, 1 \mathrm{H}, 5^{\prime \prime}-\mathrm{H}\right), 5.86(\mathrm{dt}, J=7.0$, $\left.1.0 \mathrm{~Hz}, 1 \mathrm{H}, 4^{\prime}-\mathrm{H}\right), 6.15$ (dd, $\left.J=7.0,1.0 \mathrm{~Hz}, 1 \mathrm{H}, 3^{\prime \prime}-\mathrm{H}\right), 6.20$ (dd, $J$ $\left.=7.0,1.0 \mathrm{~Hz}, 1 \mathrm{H}, 6^{\prime}-\mathrm{H}\right), 6.62\left(\mathrm{dt}, J=7.0,1.0 \mathrm{~Hz}, 1 \mathrm{H}, 4^{\prime \prime}-\mathrm{H}\right)$, 
$6.64\left(\mathrm{dt}, J=7.0,1.0 \mathrm{~Hz}, 1 \mathrm{H}, 5^{\prime} \cdot \mathrm{H}\right), 6.69(\mathrm{dd}, J=7.0,1.0 \mathrm{~Hz}, 1 \mathrm{H}$, $\left.6^{\prime \prime}-\mathrm{H}\right), 6.99\left(\mathrm{dd}, J=7.0,1.0 \mathrm{~Hz}, 1 \mathrm{H}, 3^{\prime}-\mathrm{H}\right), 7.01$ (dd, $J=7.0,1.0 \mathrm{~Hz}$, $1 \mathrm{H}, 13-\mathrm{H}), 7.02$ (dd, $J=7.0,1.0 \mathrm{~Hz}, 1 \mathrm{H}, 16-\mathrm{H}), 7.04-7.10[\mathrm{~m}, 3 \mathrm{H}$, $\left.4^{\prime \prime \prime}\left(5^{\prime \prime \prime}, 6^{\prime \prime \prime}\right)-\mathrm{H}\right], 7.18\left(\mathrm{~d}, J=7.0 \mathrm{~Hz}, 1 \mathrm{H}, 3^{\prime \prime \prime} \cdot \mathrm{H}\right), 7.61$ [dt, $J=7.0,1.0$ $\mathrm{Hz}, 2 \mathrm{H}, 14(15)-\mathrm{H}]$; (14) $\delta 3.29(\mathrm{~s}, 1 \mathrm{H}, 11-\mathrm{H}), 3.68(\mathrm{~s}, 1 \mathrm{H}, 7-\mathrm{H})$, 4.70 (dt, $J=7.0,1.0 \mathrm{~Hz}, 1 \mathrm{H}, 15-\mathrm{H}), 5.05(\mathrm{dd}, J=7.0,1.0 \mathrm{~Hz}, 1 \mathrm{H}$, $13-\mathrm{H}), 5.74\left(\mathrm{dt}, J=7.0,1.0 \mathrm{~Hz}, 1 \mathrm{H}, 5^{\prime \prime}-\mathrm{H}\right), 5.85(\mathrm{dt}, J=7.0,1.0 \mathrm{~Hz}$, $1 \mathrm{H}, 5^{\prime}-\mathrm{H}$ ), 6.02 (ddd, $\left.J=7.0,1.0,1.0 \mathrm{~Hz}, 1 \mathrm{H}, 14-\mathrm{H}\right), 6.14$ (dd, $J=$ $7.0,1.0 \mathrm{~Hz}, 1 \mathrm{H}, 3^{\prime \prime}$ - $\mathrm{H}$ ), 6.17 (dd, $\left.J=7.0,1.0 \mathrm{~Hz}, 1 \mathrm{H}, 6^{\prime}-\mathrm{H}\right), 6.36$ (ddd, $J=7.0,1.0,1.0 \mathrm{~Hz}, 1 \mathrm{H}, 16-\mathrm{H}), 6.59(\mathrm{dt}, J=7.0,1.0 \mathrm{~Hz}, 1 \mathrm{H}$, $\left.4^{\prime \prime}-\mathrm{H}\right), 6.61\left(\mathrm{dt}, J=7.0,1.0 \mathrm{~Hz}, 1 \mathrm{H}, 4^{\prime}-\mathrm{H}\right), 6.87(\mathrm{dt}, J=7.0,1.0 \mathrm{~Hz}$, $\left.1 \mathrm{H}, 5^{\prime \prime \prime} \cdot \mathrm{H}\right), 6.89$ (dd, $\left.J=7.0,1.0 \mathrm{~Hz}, 1 \mathrm{H}, 3^{\prime}-\mathrm{H}\right), 6.96(\mathrm{dt}, J=7.0$, $\left.1.0 \mathrm{~Hz}, 1 \mathrm{H}, 4^{\prime \prime \prime}-\mathrm{H}\right), 7.03$ (dd, $\left.J=7.0,1.0 \mathrm{~Hz}, 1 \mathrm{H}, 6^{\prime \prime}-\mathrm{H}\right), 7.18(\mathrm{~d}, J$ $\left.=7.0 \mathrm{~Hz}, 1 \mathrm{H}, 3^{\prime \prime \prime}-\mathrm{H}\right), 7.40\left(\mathrm{~d}, J=7.0 \mathrm{~Hz}, 1 \mathrm{H}, 6^{\prime \prime \prime}-\mathrm{H}\right)$. After hydrolysis of the anion mixture 13 and $14(24 \mathrm{mg}, 0.050 \mathrm{mmol})$ with water $(9.0 \mu \mathrm{L}, 0.50 \mathrm{mmol})$ in $1 \mathrm{~mL}$ of THF at $-78^{\circ} \mathrm{C}$ and aqueous workup, the starting material 12 was recovered almost quantitatively $(16 \mathrm{mg})$. No dimer 22 was observed in the ${ }^{1} \mathrm{H}$ NMR spectrum of the crude product.

Formation of the 1,4,7,10-Tetramethyltribenzotriquinacene (16). Reaction of 1,10-Dimethyltribenzotriquinacene (11a) with Lochmann-Schlosser Base and Subsequent Trapping with Dimethyl Sulfate. To a stirred suspension of 1,10-dimethyltribenzotriquinacene (11a; $154 \mathrm{mg}, 0.50 \mathrm{mmol}$ ) and potassium tert-butoxide (448 $\mathrm{mg}, 4.0$ mmol) in $5 \mathrm{~mL}$ of $n$-heptane were added slowly at $-30^{\circ} \mathrm{C}$ TMEDA $(1.45 \mathrm{~mL}, 10 \mathrm{mmol})$ and $n$-BuLi $(1.70 \mathrm{~mL}, 4.0 \mathrm{mmol}, 2.36 \mathrm{~N})$ in $n$-hexane. The mixture was allowed to warm to ambient temperature overnight and was stirred for an additional $24 \mathrm{~h}$ at $25^{\circ} \mathrm{C}$ and $72 \mathrm{~h}$ at $69^{\circ} \mathrm{C}$. The deeply red suspension was cooled to $20^{\circ} \mathrm{C}$ and added slowly via a steel cannula to a stirred solution of dimethyl sulfate $(950$ $\mu \mathrm{L}, 10 \mathrm{mmol}$ ) in $5 \mathrm{~mL}$ of THF at $-78^{\circ} \mathrm{C}$. After $1 \mathrm{~h}$ of stirring at this temperature, the pale yellow suspension was allowed to warm to room temperature. Toluene $(30 \mathrm{~mL})$ was added and the mixture washed three times with saturated ammonium chloride solution ( $10 \mathrm{~mL}$ each). The organic layer was dried with $\mathrm{MgSO}_{4}$, and the solvent was removed in vacuo. The crude product was purified by filtration through silica gel with toluene as the eluent and recrystallization to yield $134 \mathrm{mg}(80 \%)$ of 16 as colorless needles: $\mathrm{mp} 334{ }^{\circ} \mathrm{C}$; ${ }^{1} \mathrm{H}$ NMR $\left(300 \mathrm{MHz}, \mathrm{CDCl}_{3}\right)$ $\delta 1.36\left(\mathrm{~s}, 3 \mathrm{H}, 10-\mathrm{CH}_{3}\right), 1.67\left[\mathrm{~s}, 9 \mathrm{H}, 1(4,7)-\mathrm{CH}_{3}\right], 7.16$ [AA' part, 6 $\left.\mathrm{H}, 4^{\prime}\left(5^{\prime}\right)-\mathrm{H}\right], 7.36\left[\mathrm{BB}^{\prime}\right.$ part, $\left.6 \mathrm{H}, 3^{\prime}\left(6^{\prime}\right)-\mathrm{H}\right]$. For further spectroscopic data, see ref $23 \mathrm{~b}, \mathrm{c}$.

Preparation of 4,7-Disubstituted Tribenzodihydroacepentalenes 6. 4,7-Bis $(N$-morpholino)tribenzodihydroacepentalene (6b). To a suspension of 1,4,7-tribromotribenzotriquinacene $(17 ; 517 \mathrm{mg}, 1.0$ $\mathrm{mmol})^{23}$ in $20 \mathrm{~mL}$ of benzene was added $5 \mathrm{~mL}$ of freshly distilled morpholine. The mixture was heated to reflux for $30 \mathrm{~min}$. The reaction mixture was allowed to cool to ambient temperature, and $50 \mathrm{~mL}$ of water was added. The organic layer was extracted three times with dichloromethane $(30 \mathrm{~mL}$ each), dried over sodium sulfate, and concentrated in vacuo. After recrystallization from dichloromethane/ methanol, $367 \mathrm{mg} \mathrm{(82 \% )}$ of $\mathbf{6 b}$ was obtained as colorless crystals, $\mathrm{mp}$ $282{ }^{\circ} \mathrm{C} \mathrm{dec}$. The crystals were suitable for $\mathrm{X}$-ray analysis: IR (KBr) $v\left(\mathrm{~cm}^{-1}\right) 3063,3025,2952,2931,2889,1449,1363,1021,761 ;{ }^{\prime} \mathrm{H}$ NMR (300 MHz, $\left.\mathrm{CDCl}_{3}\right) \delta 2.85-3.05\left(\mathrm{AB}, 8 \mathrm{H}, \mathrm{CH}_{2} \mathrm{O}\right), 3.66-3.79$ $\left(\mathrm{AB}, 8 \mathrm{H}, \mathrm{CH}_{2} \mathrm{~N}\right), 7.29-7.33\left[\mathrm{~m}, 4 \mathrm{H}, 4^{\prime}\left(5^{\prime}\right)-\mathrm{H}\right], 7.19\left[\mathrm{AA}^{\prime}\right.$ part, $2 \mathrm{H}$, $\left.4^{\prime \prime}\left(5^{\prime \prime}\right)-\mathrm{H}\right], 7.39$ [BB' part, $\left.2 \mathrm{H}, 3^{\prime \prime}\left(6^{\prime \prime}\right)-\mathrm{H}\right], 7.55-7.58\left(\mathrm{~m}, 2 \mathrm{H}, 6^{\prime}-\mathrm{H}\right)$, $7.86-7.89\left(\mathrm{~m}, 2 \mathrm{H}, 3^{\prime}-\mathrm{H}\right) ;{ }^{13} \mathrm{C}$ NMR $\left(75.5 \mathrm{MHz}, \mathrm{CDCl}_{3}\right) \delta 49.3(-$, $\left.\mathrm{CH}_{2} \mathrm{~N}\right), 67.6\left(-, \mathrm{CH}_{2} \mathrm{O}\right), 78.0\left[\mathrm{C}_{9}, \mathrm{C}-4(7)\right], 122.3(+), 124.8(+), 126.8$ $(+), 127.1(+), 127.9(+), 128.0(+), 139.3\left(C_{q}\right), 143.1\left(C_{q}\right), 153.3$ $\left(\mathrm{C}_{q}\right), 155.5\left(\mathrm{C}_{\mathrm{q}}, \mathrm{C}-1\right), 162.8\left(\mathrm{C}_{\mathrm{q}}, \mathrm{C}-10\right)$; $\mathrm{MS}(\mathrm{EI}, 70 \mathrm{eV}) \mathrm{m} / \mathrm{z}$ (relative intensity) $=363$ (9), 362 (4), 339 (2), 304 (3), $276(100,[\mathrm{M}-2$ morpholinyl $\left.]^{+}\right), 182$ (2), 138 (5). Anal. Calcd for $\mathrm{C}_{30} \mathrm{H}_{28} \mathrm{~N}_{2} \mathrm{O}_{2}$ : C, 80.33; H, 6.29; N, 6.25. Found: C, 80.35; H, 6.19; N, 6.04.

Selective Preparation of Dipotassium Tribenzacepentalenediide $\left(5-K_{2}\right)$. To a suspension of tribenzotriquinacene $(4 \mathbf{a} ; 280 \mathrm{mg}, 1.0$ mmol) in $5 \mathrm{~mL}$ of $n$-heptane were added at $20{ }^{\circ} \mathrm{C}$ potassium tert-pentoxide $(7.8 \mathrm{~mL}, 7.0 \mathrm{mmol}, 0.90 \mathrm{~N})$ and 2-ethyl-1-hexyllithium $(10.0 \mathrm{~mL}, 7.0 \mathrm{mmol}, 0.70 \mathrm{~N})$. The mixture turned red and was stirred for $72 \mathrm{~h}$ at this temperature. The reaction mixture was filtered and the red residue washed three times with dry hexane $(10 \mathrm{~mL}$ each) under an argon atmosphere. The residue was dried in vacuo ( $0.01 \mathrm{Torr})$ for $1 \mathrm{~h}$ to yield $404 \mathrm{mg}$ of crude $\mathbf{5}-\mathbf{K}_{2},{ }^{49}$ which can be directly used for subsequent reactions: ${ }^{1} \mathrm{H}$ NMR $\left(400 \mathrm{MHz},\left[\mathrm{D}_{10}\right] \mathrm{DME}\right) \delta 6.69\left[\mathrm{AA}^{\prime}\right.$ part, $\left.6 \mathrm{H}, 4^{\prime}\left(5^{\prime}\right)-\mathrm{H}\right], 7.74\left[\mathrm{XX}^{\prime}\right.$ part, $\left.6 \mathrm{H}, 3^{\prime}\left(6^{\prime}\right)\right] ;{ }^{13} \mathrm{C} \mathrm{NMR}(100.6 \mathrm{MHz}$, [D $\left.D_{10}\right] \mathrm{DME}, \mathrm{C}-\mathrm{H}$ correlation: SF1 $\left.=400 \mathrm{MHz}, \mathrm{SF} 2=100.6 \mathrm{MHz}\right) \delta$ $99.9\left[\mathrm{C}_{\mathrm{q}}, \mathrm{C}-1(4,7)\right], 113.2\left[+, \mathrm{C}-3^{\prime}\left(6^{\prime}\right)\right], 119.6\left[+, \mathrm{C}-4^{\prime}\left(5^{\prime}\right)\right], 137.8\left[\mathrm{C}_{\mathrm{q}}\right.$, C-2(3,5,6,8,9)], $173.2\left(\mathrm{C}_{\mathbf{q}}, \mathrm{C}-10\right)$. In the COLOC spectra the following crosspeaks were observed: $3^{\prime}\left(6^{\prime}\right)$-H with $\mathrm{C}-1(4,7), 3^{\prime}\left(6^{\prime}\right)-\mathrm{H}$ with C-2(3,5,6,8,9), $3^{\prime}\left(6^{\prime}\right)-\mathrm{H}$ with $\mathrm{C}-4^{\prime}\left(5^{\prime}\right), 4^{\prime}\left(5^{\prime}\right)-\mathrm{H}$ with $\mathrm{C}-2(3,5,6,8,9)$, and $4^{\prime}\left(5^{\prime}\right)-\mathrm{H}$ with $\mathrm{C}-3^{\prime}\left(6^{\prime}\right)$.

General Procedure for the Reaction of Dipotassium Tribenzacepentalenediide (5-K $)$ with Electrophiles (GP3). To a stirred solution of the respective electrophile ( $2.5 \mathrm{mmol}, 5$ equiv) in $5 \mathrm{~mL}$ of the indicated solvent was added dropwise via syringe a suspension of dipotassium tribenzacepentalenediide $\left(5-\mathrm{K}_{2} ; 202 \mathrm{mg}, 0.50 \mathrm{mmol}\right)^{49}$ in $5 \mathrm{~mL}$ of $n$-hexane at $-78^{\circ} \mathrm{C}$; the red mixture was stirred for $1 \mathrm{~h}$ at $-78{ }^{\circ} \mathrm{C}$ and then allowed to warm slowly to room temperature, while the color changed to pale yellow. The conditions for workup were chosen according to the stability of the product. Less sensitive 4,7disubstituted tribenzodihydroacepentalenes 6 were treated as follows: The reaction mixture was diluted with $50 \mathrm{~mL}$ of $n$-hexane and washed three times with brine ( $10 \mathrm{~mL}$ each). The organic layer was dried with $\mathrm{MgSO}_{4}$, and the solvent was removed in vacuo. The crude product was purified by flash column chromatography (eluent $=$ petroleum ether/ethyl acetate, 50:1).

4,7-Bis(trimethylsilyl)tribenzodihydroacepentalene (6c). The product obtained from $\mathbf{5} \cdot \mathbf{K}_{\mathbf{2}}$ and chlorotrimethylsilane $(340 \mu \mathrm{L})$ according to GP3, using hexane as the solvent, yielded $203 \mathrm{mg}$ (96\%) of $6 \mathrm{c}$ as colorless needles, mp $191{ }^{\circ} \mathrm{C}$. Single crystals for X-ray structure analysis were obtained by recrystallization from hexane: IR (KBr) $v$ $\left(\mathrm{cm}^{-1}\right) 3060,2955,2900,1600,1560,1540,1470,1460,1445,1265$, $1255,1205,845,750,705 ;{ }^{1} \mathrm{H}$ NMR $\left(400 \mathrm{MHz},\left[\mathrm{D}_{8}\right] \mathrm{THF}\right) \delta 0.22[\mathrm{~s}$, $18 \mathrm{H}, \mathrm{Si}\left(\mathrm{CH}_{3}\right)_{3}$ ], 7.10 [AA' part, $\left.2 \mathrm{H}, 4^{\prime \prime}\left(5^{\prime \prime}\right)-\mathrm{H}\right], 7.14(\mathrm{dt}, J=7.5,1.0$ $\left.\mathrm{Hz}, 2 \mathrm{H}, 4^{\prime}-\mathrm{H}\right), 7.27\left(\mathrm{dt}, J=7.5,1.0 \mathrm{~Hz}, 2 \mathrm{H}, 5^{\prime}-\mathrm{H}\right), 7.42\left[\mathrm{BB}^{\prime}\right.$ part, $\left.2 \mathrm{H}, 3^{\prime \prime}\left(6^{\prime \prime}\right)-\mathrm{H}\right), 7.69$ (dd, $\left.J=7.5,1.0 \mathrm{~Hz}, 2 \mathrm{H}, 6^{\prime}-\mathrm{H}\right), 7.72$ (dd, $J=$ $\left.7.5,1.0 \mathrm{~Hz}, 2 \mathrm{H}, 3^{\prime}-\mathrm{H}\right) ;{ }^{13} \mathrm{C} \mathrm{NMR}\left(100.6 \mathrm{MHz},\left[\mathrm{D}_{8}\right] \mathrm{THF}, \mathrm{DEPT}\right) \delta$ $0.5\left[+, \mathrm{Si}\left(\mathrm{CH}_{3}\right)_{3}\right], 61.6\left[\mathrm{C}_{\mathrm{q}}, \mathrm{C}-4(7)\right], 121.6(+), 124.5(+), 125.9(+)$, $125.9(+), 128.9(+), 129.1(+), 143.7\left(C_{q}\right), 148.8\left(C_{q}\right), 156.5\left(C_{q}\right.$, C-1), $159.4\left(\mathrm{C}_{\mathrm{q}}\right), 182.3\left(\mathrm{C}_{\mathrm{q}}, \mathrm{C}-10\right)$; $\mathrm{MS}(\mathrm{EI}, 70 \mathrm{eV}) \mathrm{m} / \mathrm{z}$ (relative intensity) $=423(7), 422\left(22, \mathrm{M}^{+}\right), 349\left(18,\left[\mathrm{M}-\mathrm{Si}\left(\mathrm{CH}_{3}\right)_{3}\right]^{+}\right), 335$ (28), $334(100), 319(20), 276\left(5,\left[\mathrm{M}-2 \mathrm{Si}\left(\mathrm{CH}_{3}\right)_{3}\right]^{+}\right), 73$ (28). Anal. Calcd for $\mathrm{C}_{28} \mathrm{H}_{30} \mathrm{Si}_{2}$ : C, 79.56; H, 7.15. Found: C, 79.65; H, 7.09.

Dimethyl Tribenzodihydroacepentalene-4,7-dicarboxylate (6d). The product obtained from $5 \cdot \mathrm{K}_{2}$ and methyl chloroformate $(192 \mu \mathrm{L})$ according to GP3, using THF as the solvent, yielded $114 \mathrm{mg} \mathrm{(58 \% )} \mathrm{of}$ 6d as colorless needles, $\mathrm{mp} 173{ }^{\circ} \mathrm{C}$ dec. Single crystals for X-ray structure analysis were obtained by recrystallization from ethyl acetate under an argon atmosphere: $\mathrm{IR}(\mathrm{KBr}) \nu\left(\mathrm{cm}^{-1}\right) 3050,3010,2950,1735$, $1440,1260,1110,1030,1010,785,760,705 ;{ }^{1} \mathrm{H}$ NMR $(250 \mathrm{MHz}$, $\left.\mathrm{CDCl}_{3}\right) \delta 3.76\left(\mathrm{~s}, 6 \mathrm{H}, \mathrm{CO}_{2} \mathrm{CH}_{3}\right), 7.25\left(\mathrm{dt}, J=7.5,1.0 \mathrm{~Hz}, 2 \mathrm{H}, 5^{\prime}-\mathrm{H}\right)$ $7.40\left[\mathrm{~m}_{\mathrm{c}}, 4 \mathrm{H}, 4^{\prime}\left(4^{\prime \prime}, 5^{\prime \prime}\right)-\mathrm{H}\right], 7.58\left[\mathrm{~m}_{\mathrm{c}}, 2 \mathrm{H}, 3^{\prime \prime}\left(6^{\prime \prime}\right)-\mathrm{H}\right], 7.68(\mathrm{dd}, J=$ $\left.7.5,1.0 \mathrm{~Hz}, 2 \mathrm{H}, 6^{\prime}-\mathrm{H}\right), 7.98\left(\mathrm{dd}, J=7.5,1.0 \mathrm{~Hz}, 2 \mathrm{H}, 3^{\prime}-\mathrm{H}\right) ;{ }^{13} \mathrm{C}$ NMR (62.9 MHz, $\left.\mathrm{CDCl}_{3}, \mathrm{DEPT}\right) \delta 52.8\left(+, \mathrm{CO}_{2} \mathrm{CH}_{3}\right), 64.2\left[\mathrm{C}_{\mathrm{q}}\right.$, C-4(7)], $122.6(+), 125.1(+), 126.1(+), 127.6(+), 128.6(+), 128.8$ $(+), 139.7\left(C_{q}\right), 143.2\left(C_{q}\right), 151.1\left(C_{q}\right), 156.5\left(C_{q}, C-1\right), 158.3\left(C_{q}\right.$, $\mathrm{C}-10), 171.1\left(\mathrm{C}_{\mathrm{q}}, \mathrm{CO}_{2} \mathrm{CH}_{3}\right) ; \mathrm{MS}(\mathrm{EI}, 70 \mathrm{eV}) \mathrm{m} / \mathrm{z}$ (relative intensity) = 395 (12), $394\left(39, \mathrm{M}^{+}\right), 351$ (22), 337 (30), 336 (100), 293 (27), 276 (95, $\left.\left[\mathrm{M}-2 \mathrm{CO}_{2} \mathrm{CH}_{3}\right]^{+}\right), 43(65)$; correct HRMS for $\mathrm{C}_{26} \mathrm{H}_{18} \mathrm{O}_{4}$, calcd 394.1205

4,7-Bis(phenylselenyl)tribenzodihydroacepentalene (6e). The product obtained from $\mathbf{5}-\mathbf{K}_{\mathbf{2}}$ and phenylselenyl chloride $(479 \mathrm{mg}$ ) according to GP3, using THF as the solvent, yielded $51 \mathrm{mg}(17 \%)$ of $6 \mathrm{e}$ as a pale yellow solid, $\mathrm{mp} 185^{\circ} \mathrm{C}$ dec. Part of the product decomposed on the column. Crystals were obtained by recrystallization from hexane/ THF under an argon atmosphere: IR $(\mathrm{KBr}) v\left(\mathrm{~cm}^{-1}\right) 3060,1655,1576$, $1475,1455,1435,1020,850,750,740,705,685 ;{ }^{1} \mathrm{H}$ NMR $(250 \mathrm{MHz}$, $\left.\mathrm{CDCl}_{3}\right) \delta 6.99(\mathrm{t}, J=7.0 \mathrm{~Hz}, 4 \mathrm{H}$, phenyl-H) $7.25(\mathrm{dt}, J=7.5,1.0$ $\left.\mathrm{Hz}, 2 \mathrm{H}, 5^{\prime}-\mathrm{H}\right) 7.18-7.35$ [m, $10 \mathrm{H}, 4^{\prime}\left(6^{\prime}, 3^{\prime \prime}, 4^{\prime \prime}, 5^{\prime \prime}, 6^{\prime \prime}\right.$, phenyl)-H], 7.45 $\left(\mathrm{m}_{\mathrm{c}}, 4 \mathrm{H}\right.$, phenyl-H), 7.98 (dd, $\left.J=7.5,1.0 \mathrm{~Hz}, 2 \mathrm{H}, 3^{\prime}-\mathrm{H}\right) ;{ }^{13} \mathrm{C}$ NMR $\left(62.9 \mathrm{MHz}, \mathrm{CDCl}_{3}, \mathrm{DEPT}\right) \delta 58.5\left[\mathrm{C}_{\mathrm{q}}, \mathrm{C}-4(7)\right], 122.1(+), 125.7(+)$, $125.9(+), 127.3(+), 127.7(+), 127.8(+$, C-phenyl), $128.4(+$, C-phenyl), $128.9(+), 129.9\left(\mathrm{C}_{\mathrm{q}}\right), 134.7\left(+, \mathrm{C}\right.$-phenyl), $138.9\left(\mathrm{C}_{\mathrm{q}}\right.$, C-phenyl), $143.6\left(\mathrm{C}_{\mathrm{q}}\right), 154.1\left(\mathrm{C}_{\mathrm{q}}\right), 155.0\left(\mathrm{C}_{\mathrm{q}}, \mathrm{C}-1\right), 198.9\left(\mathrm{C}_{\mathrm{q}}, \mathrm{C}-10\right)$; MS (EI, $70 \mathrm{eV}) \mathrm{m} / z$ (relative intensity) $=433\left(40,[\mathrm{M}-\mathrm{SePh}]^{+}\right), 276$ $\left(100,[\mathrm{M}-2 \mathrm{SePh}]^{+}\right), 274(18)$; correct HRMS for $\mathrm{C}_{28} \mathrm{H}_{17}{ }^{80} \mathrm{Se}^{+}$ (fragment ion peak), calcd 433.0495 . 
4,7-Bis(trimethylstannyl)tribenzodihydroacepentalene (6f). To a suspension of the crude dipotassium salt $\mathbf{5 - K _ { 2 }}(404 \mathrm{mg}, 1.0 \mathrm{mmol})$ in $10 \mathrm{~mL}$ of ether was added at $-78{ }^{\circ} \mathrm{C} 398 \mathrm{mg}(2.0 \mathrm{mmol})$ of trimethylstannyl chloride in $20 \mathrm{~mL}$ of ether. The mixture was allowed to warm to ambient temperature and filtered under argon. The residue was suspended again in $10 \mathrm{~mL}$ of ether and treated with $398 \mathrm{mg}(2$ mmol) of trimethylstannyl chloride in $20 \mathrm{~mL}$ of ether at $-78^{\circ} \mathrm{C}$. The mixture was allowed to warm slowly to ambient temperature. After filtration through a P4 sintered glass under argon the solution was concentrated and the remaining yellow oil purified by low-temperature $\left(-30^{\circ} \mathrm{C}\right)$ crystallization from hexane to give $254 \mathrm{mg}(42 \%)$ of $6 \mathrm{f}$ as a yellow solid: ${ }^{1} \mathrm{H}$ NMR $\left(400 \mathrm{MHz},\left[\mathrm{D}_{3}\right]\right.$ acetonitrile) $\delta 0.20[\mathrm{~s}, 18 \mathrm{H}$, $\mathrm{Sn}\left(\mathrm{CH}_{3}\right)_{3}$ ], 7.04 [AA' part, $2 \mathrm{H}, 4^{\prime \prime}\left(5^{\prime \prime}\right)-\mathrm{H}$ ], $7.17(\mathrm{dt}, J=7.5,1.0 \mathrm{~Hz}$, $\left.2 \mathrm{H}, 5^{\prime}-\mathrm{H}\right), 7.30\left(\mathrm{dt}, J=7.5,1.0 \mathrm{~Hz}, 2 \mathrm{H}, 4^{\prime}-\mathrm{H}\right), 7.46\left[\mathrm{BB}^{\prime}\right.$ part, $2 \mathrm{H}$, $\left.3^{\prime \prime}\left(6^{\prime \prime}\right)-\mathrm{H}\right], 7.67$ (dd, $\left.J=7.5,1 \mathrm{~Hz}, 2 \mathrm{H}, 3^{\prime}-\mathrm{H}\right), 7.73$ (dd, $J=7.5,1.0$ $\left.\mathrm{Hz}, 2 \mathrm{H}, 6^{\prime}-\mathrm{H}\right) ;{ }^{13} \mathrm{C}$ NMR $\left(100.6 \mathrm{MHz},\left[\mathrm{D}_{3}\right.\right.$ ] acetonitrile, DEPT) $\delta-6.6$ $\left[+, \mathrm{Sn}\left(\mathrm{CH}_{3}\right)_{3}\right], 62.6\left[\mathrm{C}_{\mathrm{q}}, \mathrm{C}-4(7)\right], 121.8(+), 124.7(+), 125.4(+)$, $125.5(+), 126.7(+), 126.9(+), 142.6\left(\mathrm{C}_{q}\right), 149.7\left(\mathrm{C}_{q}\right), 151.1\left(\mathrm{C}_{\mathrm{q}}\right.$, C-1), $158.1\left(\mathrm{C}_{q}\right), 187.6\left(\mathrm{C}_{q}, \mathrm{C}-10\right)$; MS (EI, $\left.70 \mathrm{eV}\right) \mathrm{m} / \mathrm{z}$ (relative intensity) $=604\left(3, \mathrm{M}^{+}\right), 441(15), 426(25), 411(8), 396(7), 289(8)$, $276\left(100,\left[\mathrm{M}-\mathrm{Sn}\left(\mathrm{CH}_{3}\right)_{3}\right]^{+}\right), 165(18)$. The isotopic pattern of the molecular ions $m / z=594-615$ clearly confirmed the molecular formula $\mathrm{C}_{28} \mathrm{H}_{30} \mathrm{Sn}_{2}$.

Reactions of 4,7-Bis(trimethylsilyl)tribenzodihydroacepentalene (6c). 1-Hydroxy-4,7-bis(trimethylsilyl)tribenzotriquinacene (18a). To a solution of $6 \mathbf{c}(211 \mathrm{mg}, 0.50 \mathrm{mmol})$ in $10 \mathrm{~mL}$ of THF was added sulfuric acid $(1 \mathrm{~mL}, 50 \%)$. The reaction mixture was stirred at $50^{\circ} \mathrm{C}$ for $15 \mathrm{~h}$. After addition of $50 \mathrm{~mL}$ of ether, the mixture was extracted three times with saturated $\mathrm{NaHCO}_{3}$ solution $(10 \mathrm{~mL}$ each). The organic layer was dried with $\mathrm{MgSO}_{4}$ and concentrated in vacuum. The crude material was purified by column chromatography (eluent $=$ hexane/ ethyl acetate, $10: 1)$ to yield $136 \mathrm{mg}(62 \%)$ of $18 \mathrm{a}$ as colorless crystals: $\mathrm{mp} 182^{\circ} \mathrm{C}$; IR $(\mathrm{KBr}) v\left(\mathrm{~cm}^{-1}\right) 3580,3480,3050,3010,2940$, $1610,1465,1450,1250,890,840,760 ;{ }^{1} \mathrm{H}$ NMR $\left(400 \mathrm{MHz}, \mathrm{CD}_{2} \mathrm{Cl}_{2}\right)$ $\delta 0.12\left[\mathrm{~s}, 18 \mathrm{H}, \mathrm{Si}\left(\mathrm{CH}_{3}\right)_{3}\right], 2.54(\mathrm{~s}, 1 \mathrm{H}, \mathrm{OH}), 3.94(\mathrm{~s}, 1 \mathrm{H}, 10-\mathrm{H}), 7.29$ $\left(\mathrm{m}_{\mathrm{c}}, 6 \mathrm{H}\right.$, aromatic- $\left.\mathrm{H}\right), 7.37\left(\mathrm{~m}_{\mathrm{c}}, 2 \mathrm{H}\right.$, aromatic- $\left.\mathrm{H}\right), 7.45\left(\mathrm{~m}_{\mathrm{c}}, 2 \mathrm{H}\right.$, aromatic- $\mathrm{H}), 7.52\left(\mathrm{~m}_{\mathrm{c}}, 2 \mathrm{H}\right.$, aromatic- $\left.\mathrm{H}\right) ;{ }^{13} \mathrm{C} \mathrm{NMR}\left(100.6 \mathrm{MHz}, \mathrm{CD}_{2-}\right.$ $\mathrm{Cl}_{2}$, DEPT) $\delta-1.93\left[+, \mathrm{Si}\left(\mathrm{CH}_{3}\right)_{3}\right], 55.4\left[\mathrm{C}_{\mathrm{q}}, \mathrm{C} 4(7)\right], 68.1(+, \mathrm{C}-10)$, $95.2\left(\mathrm{C}_{q}, \mathrm{C}-1\right), 123.4(+), 124.3(+), 124.6(+), 127.0(+), 127.1(+)$, $128.8(+), 147.4\left(\mathrm{C}_{q}\right), 147.7\left(\mathrm{C}_{q}\right), 148.1\left(\mathrm{C}_{q}\right) ;$ MS (EI, $\left.70 \mathrm{eV}\right) \mathrm{m} / \mathrm{z}$ (relative intensity) $=440\left(0.04, \mathrm{M}^{+}\right), 367\left(2,\left[\mathrm{M}-\mathrm{Si}\left(\mathrm{CH}_{3}\right)_{3}\right]^{+}\right), 351$ (15), 350 (43), 335 (10), 276 (17), 275 (14), 73 (100). Anal. Calcd for $\mathrm{C}_{28} \mathrm{H}_{32} \mathrm{OSi}_{2}$ : C, 76.31; $\mathrm{H}, 7.32$. Found: C, 76.32; $\mathrm{H}, 7.42$.

1-Methoxy-4,7-bis(trimethylsilyl)tribenzotriquinacene (18b) and 1-Methoxy-4-(trimethylsilyl)tribenzotriquinacene (19). To a solution of $6 \mathrm{c}(211 \mathrm{mg}, 0.50 \mathrm{mmol})$ in $5 \mathrm{~mL}$ of THF were added $15 \mathrm{~mL}$ of $\mathrm{MeOH}$ and $1 \mathrm{~mL}$ of concentrated sulfuric acid. The reaction mixture was stirred at $20^{\circ} \mathrm{C}$ for $15 \mathrm{~h}$. After addition of $50 \mathrm{~mL}$ of ether, the mixture was extracted three times with saturated $\mathrm{NaHCO}_{3}$ solution (10 $\mathrm{mL}$ each). The organic layer was dried with $\mathrm{MgSO}_{4}$ and concentrated in vacuo. The crude material was purified by column chromatography (eluent $=$ hexane/ethyl acetate, 50:1) to obtain two fractions with similar $R_{f}$ values. F1 $\left(R_{f}=0.33\right): 162 \mathrm{mg}(71 \%)$ of $18 \mathrm{~b}$; colorless crystals; mp $141{ }^{\circ} \mathrm{C}$; IR (KBr) $v\left(\mathrm{~cm}^{-1}\right) 3050,3010,2940,2900,2820,1595$, $1580,1465,1450,1250,1080,830,750 ;{ }^{1} \mathrm{H}$ NMR $\left(400 \mathrm{MHz}, \mathrm{CDCl}_{3}\right)$ $\delta 0.16\left[\mathrm{~s}, 18 \mathrm{H}, \mathrm{Si}\left(\mathrm{CH}_{3}\right)_{3}\right], 3.45\left(\mathrm{~s}, 3 \mathrm{H}, \mathrm{OCH}_{3}\right), 4.20(\mathrm{~s}, 1 \mathrm{H}, 10-\mathrm{H})$, $7.14\left(\mathrm{~m}_{\mathrm{c}}, 6 \mathrm{H}\right.$, aromatic-H), $7.29\left(\mathrm{~m}_{\mathrm{c}}, 2 \mathrm{H}\right.$, aromatic- $\left.\mathrm{H}\right), 7.38\left(\mathrm{~m}_{\mathrm{c}}, 2 \mathrm{H}\right.$, aromatic- $\mathrm{H}), 7.42\left(\mathrm{~m}_{\mathrm{c}}, 2 \mathrm{H}\right.$, aromatic-H); ${ }^{13} \mathrm{C} \mathrm{NMR}\left(100.6 \mathrm{MHz}, \mathrm{CDCl}_{3}\right.$, DEPT) $\delta-1.4\left[+, \mathrm{Si}\left(\mathrm{CH}_{3}\right)_{3}\right], 53.3\left(+, \mathrm{OCH}_{3}\right), 55.4\left[\mathrm{C}_{\mathrm{q}}, \mathrm{C}-4(7)\right], 61.7$ $(+, \mathrm{C}-10), 101.7\left(\mathrm{C}_{\mathrm{g}}, \mathrm{C}-1\right), 124.7(+), 124.8(+), 125.1(+), 127.1$ $(+), 127.2(+), 129.1(+), 145.8\left(C_{q}\right), 148.7\left(C_{q}\right), 149.1\left(C_{q}\right) ;$ MS (EI, $70 \mathrm{eV}) \mathrm{m} / \mathrm{z}$ (relative intensity) $=455(5), 454\left(16, \mathrm{M}^{+}\right), 440(19), 439$ (51), $351(30), 350\left(100,\left[\mathrm{M}-\mathrm{Si}\left(\mathrm{CH}_{3}\right)_{3}-\mathrm{OCH}_{3}\right]^{+}\right), 335(17), 277$ (32), 276 (21), 73 (33). Anal. Calcd for $\mathrm{C}_{29} \mathrm{H}_{34} \mathrm{OSi}_{2}$ : C, 76.59; $\mathrm{H}$, 7.54. Found: C, $76.75 ; \mathrm{H}, 7.52$. F2 $\left(R_{f}=0.28\right) ; 6 \mathrm{mg}(3 \%)$ of 19 ; colorless oil; ${ }^{1} \mathrm{H}$ NMR $\left(400 \mathrm{MHz}, \mathrm{CDCl}_{3}\right) \delta 0.11\left[\mathrm{~s}, 9 \mathrm{H}, \mathrm{Si}\left(\mathrm{CH}_{3}\right)_{3}\right]$, $3.27\left(\mathrm{~s}, 3 \mathrm{H}, \mathrm{OCH}_{3}\right), 4.20(\mathrm{~d}, J=9.5 \mathrm{~Hz}, 1 \mathrm{H}, 7-\mathrm{H}), 5.01(\mathrm{~d}, J=9.5$ $\mathrm{Hz}, 1 \mathrm{H}, 10-\mathrm{H}), 7.14\left(\mathrm{~m}_{\mathrm{c}}, 3 \mathrm{H}\right.$, aromatic- $\left.\mathrm{H}\right), 7.26\left(\mathrm{~m}_{\mathrm{c}}, 3 \mathrm{H}\right.$, aromatic$\mathrm{H}), 7.46\left(\mathrm{~m}_{\mathrm{c}}, 2 \mathrm{H}\right.$, aromatic-H), $7.59\left(\mathrm{~m}_{\mathrm{c}}, 4 \mathrm{H}\right.$, aromatic-H $) ;{ }^{13} \mathrm{C} \mathrm{NMR}$ $\left(62.5 \mathrm{MHz}, \mathrm{CDCl}_{3}, \mathrm{DEPT}\right) \delta-2.9\left[+, \mathrm{Si}\left(\mathrm{CH}_{3}\right)_{3}\right], 52.0\left(+, \mathrm{OCH}_{3}\right)$, $55.0(+, C-7), 55.8\left(\mathrm{C}_{\mathrm{q}}, \mathrm{C}-4\right), 59.5(+, \mathrm{C}-10), 101.0\left(\mathrm{C}_{\mathrm{q}}, \mathrm{C}-1\right), 124.4$, $124.6,125.0,125.1,125.2,125.4,127.2,127.3,128.1,128.3,129.6$, $129.8(+, \mathrm{C}$-aromatic $), 144.7,146.3,146.7,148.0,148.4,148.8\left(\mathrm{C}_{9}\right.$,
$\mathrm{C}$-aromatic); MS (EI, $70 \mathrm{eV}) \mathrm{m} / \mathrm{z}$ (relative intensity) $=351(0.4,[\mathrm{M}-$ $\left.\mathrm{OCH}_{3}\right]^{+}$), 350 (0.3), 309 (5), 279 (27), 278 (100), 277 (16), $276(13)$, 73 (69), 45 (21).

Reactions of 4,7-Bis(trimethylstannyl)tribenzodihydroacepentalene (6f). Homolytic Cleavage of the Stannyl Substituents in $6 \mathrm{f}$ by Irradiation and Trapping with tert-Butyl Mercaptan. In a Pyrex NMR tube a mixture of 4,7-bis(trimethylstannyl)tribenzodihydroacepentalene (6f; $10 \mathrm{mg}, \mathrm{ca} .0 .015 \mathrm{mmol}$ ), $\mathrm{CDCl}_{3}(0.7 \mathrm{~mL}$ ), and tert-butyl mercaptan $(150 \mu \mathrm{L})$ was prepared under an argon atmosphere. The tube was then irradiated with a $450 \mathrm{~W}$ mercury high-pressure lamp (Hanovia, type $679 \mathrm{~A}-36$ ) at $0{ }^{\circ} \mathrm{C}$. The reaction was monitored by ${ }^{~} \mathrm{H}$ NMR spectroscopy $(250 \mathrm{MHz})$ in time intervals of $10 \mathrm{~min}$. After 30 min the starting material had vanished, and instead a sharp singlet at $5.23 \mathrm{ppm}$ for the bridgehead protons of 22 was observed. Besides, broad signals in the region of 7.0-7.5 ppm were observed, which were attributed to oligomeric and polymeric decomposition products. The same broad signals (7.0-7.5 ppm), but no signals of 22 , were observed in the spectrum of a reference sample which was prepared without tertbutyl mercaptan but irradiated under exactly the same conditions.

Dilithium Tribenzacepentalenediide (5- $\mathbf{L i}$ ). To a solution of 302 $\mathrm{mg}(0.50 \mathrm{mmol})$ of the bisstannyl derivative $6 \mathrm{f}$ in $5 \mathrm{~mL}$ of DME was added $3.0 \mathrm{~mL}$ ( $1.5 \mathrm{mmol}$ ) of a $0.50 \mathrm{M}$ solution of methyllithium (MeLi) in DME with vigorous stirring at $-78^{\circ} \mathrm{C}$. The MeLi solution was freshly prepared by evaporating an ethereal solution to dryness with an argon stream and adding the appropriate amount of DME. The mixture was then allowed to warm to ambient temperature and filtered through a P4 sintered glass under argon. Part of the solvent was removed under reduced pressure. Then the solution was immediately cooled to $-30^{\circ} \mathrm{C}$ for $2-3$ days to yield $240 \mathrm{mg}(81 \%)$ of the dilithium salt (DME complex) $\mathbf{5}-\mathrm{Li}_{2}$ as colorless crystals: ${ }^{1} \mathrm{H}$ NMR $(400 \mathrm{MHz}$, $\left.\left[\mathrm{D}_{8}\right] \mathrm{THF},-60^{\circ} \mathrm{C}\right) \delta 6.55\left[\mathrm{AA}^{\prime}\right.$ part, $\left.6 \mathrm{H}, 4^{\prime}\left(5^{\prime}\right)-\mathrm{H}\right], 7.58\left[\mathrm{XX}^{\prime}\right.$ part, 6 $\left.\mathrm{H}, 3^{\prime}\left(6^{\prime}\right)\right]$; the peaks at $3.17,3.18,3.22$, and $3.26 \mathrm{ppm}$ were assigned to dimethoxyethane; ${ }^{13} \mathrm{C}$ NMR $\left(100.7 \mathrm{MHz},\left[\mathrm{D}_{8}\right] \mathrm{THF},-60^{\circ} \mathrm{C}, \mathrm{DEPT}\right)$ $\delta 100.9$ [q, C-1(4,7)], $112.5\left[+, \mathrm{C}-3^{\prime}\left(6^{\prime}\right)\right.$ ], $118.1\left[+, \mathrm{C}-4^{\prime}\left(5^{\prime}\right)\right], 140.5$ [q, C-2(3,5,6,8,9)], $177.0(\mathrm{q}, \mathrm{C}-10)$; the peaks at $58.8,72.1$, and 72.2 ppm were assigned to dimethoxyethane; ${ }^{7} \mathrm{Li}$ NMR $(194.4 \mathrm{MHz}$, [D 8 ]THF) $\delta-1.7$ (br s).

Reaction of Tribenzacepentalene Dianion (5) with Water. Generation of 4,7-Dihydrotribenzacepentalene Monomer (6a). A solution of dipotassium tribenzacepentalenediide $\left(\mathbf{5}-\mathbf{K}_{2} ; 10 \mathrm{mg}, 0.025\right.$ mmol $)^{49}$ in $0.5 \mathrm{~mL}$ of $\left[\mathrm{D}_{10}\right] \mathrm{DME}$ was prepared under nitrogen (glovebox) in an NMR tube. After cooling to $-60^{\circ} \mathrm{C}$, the sample was reopened under an argon atmosphere and a solution of water $(0.5$ $\mu \mathrm{L}, 0.030 \mathrm{mmol}$ ) in $0.2 \mathrm{~mL}$ of $\left[\mathrm{D}_{10}\right] \mathrm{DME}$ added slowly, running along the precooled glass wall of the NMR tube before reaching the dissolved sample of dianion $\mathbf{5 - K _ { 2 }}$. Then the tube was sealed under argon at -60 ${ }^{\circ} \mathrm{C}$ and directly transferred into the precooled transmitter of the NMR spectrometer: 'H NMR (500 MHz, [D $\left.\left.\mathrm{D}_{10}\right] \mathrm{DME},-60^{\circ} \mathrm{C}\right) \delta 4.58[\mathrm{~s}, 2$ $\mathrm{H}, 4(7)-\mathrm{H}], 7.00\left[\mathrm{~m}_{\mathrm{c}}, 2 \mathrm{H}, 4^{\prime \prime}\left(5^{\prime \prime}\right)-\mathrm{H}\right], 7.12\left(\mathrm{~m}_{\mathrm{c}}, 2 \mathrm{H}, 4^{\prime}-\mathrm{H}\right), 7.23$ (dt, $J$ $\left.=7.5,1.0 \mathrm{~Hz}, 2 \mathrm{H}, 5^{\prime}-\mathrm{H}\right), 7.41-7.47\left[\mathrm{~m}, 4 \mathrm{H}, 6^{\prime}\left(3^{\prime \prime}, 6^{\prime \prime}\right)-\mathrm{H}\right], 7.58\left(\mathrm{~m}_{\mathrm{c}}\right.$, $\left.2 \mathrm{H}, 3^{\prime}-\mathrm{H}\right)$. The spectrum also showed signals of a small amount of unreacted dianion 5 , of aliphatic impurities, ${ }^{49}$ and of dimer 22 . When the sample was warmed to room temperature, the signals of $6 \mathbf{a}$ disappeared and the signals of the dimer 22 were observed instead (see below). Attempts to record a ${ }^{13} \mathrm{C}$ NMR spectrum of $6 \mathrm{a}$ after quenching the sample failed in the case of the dipotassium dianion $\mathbf{5}-\mathbf{K}_{\mathbf{2}}$ due to its low solubility in $\left[\mathrm{D}_{10}\right] \mathrm{DME}$ at $-60^{\circ} \mathrm{C}$. By quenching the more soluble dilithium tribenzacepentalenediide $\left(\mathbf{5}-\mathbf{L i}_{2}\right)$ at $-78{ }^{\circ} \mathrm{C}$ with methanol in $\left[\mathrm{D}_{8}\right] \mathrm{THF}$, the concentration of $6 \mathbf{6}$ was sufficiently high to achieve its observation by ${ }^{13} \mathrm{C}$ NMR spectroscopy. However, this sample contained the dimer $\mathbf{2 2}$ as a major product due to the high concentration of the reactants in the NMR tube. We here give the ${ }^{13} \mathrm{C}$ NMR peaks which disappeared after warming the sample to ambient temperature and are assigned to the monomer $6 \mathrm{a}$ (see text): ${ }^{13} \mathrm{C}$ NMR $\left(125.7 \mathrm{MHz},\left[\mathrm{D}_{8}\right] \mathrm{THF},-60^{\circ} \mathrm{C}\right) \delta 58.0,125.9,126.1,127.9,128.0$, $128.3,128.4,128.6,128.8,145.5,146.7,150.0$.

Reactions of 4,7-Dihydrotribenzacepentalene (6a). 3:4,6:7,12: $13,15: 16,17: 18,19: 20$-Hexabenzoheptacyclo[9.5.2.2.28. $\left.0^{1,10} \cdot 0^{29} \cdot 0^{5,9} \cdot 0^{10,14}\right]$ icosa-3,6,12,15,17,19-hexaene (22) [4,7-Dihydrotribenzacepentalene Dimer]. To a solution of water $(90 \mu \mathrm{L}, 5.0 \mathrm{mmol})$ in $25 \mathrm{~mL}$ of THF was added slowly at $-78{ }^{\circ} \mathrm{C}$ a suspension of dipotassium tribenzacepentalenediide $\left(5-\mathrm{K}_{2} ; 240 \mathrm{mg}, 0.50 \mathrm{mmol}\right)^{49}$ in $5 \mathrm{~mL}$ of $n$-hexane. The red solution turned yellow and became colorless after warming to 
ambient temperature. The reaction mixture was diluted with $50 \mathrm{~mL}$ of ether and extracted twice with saturated ammonium chloride solution (20 $\mathrm{mL}$ each). The organic layer was dried over $\mathrm{MgSO}_{4}$ and concentrated in vacuo. The crude white solid was recrystallized from THF/hexane to give $270 \mathrm{mg}$ ( $97 \%$ ) of $\mathbf{2 2}$ as colorless crystals, mp 338 ${ }^{\circ} \mathrm{C}$ dec. Single crystals for $\mathrm{X}$-ray structure analysis were obtained by recrystallization from THF/hexane under an argon atmosphere: IR $(\mathrm{KBr}) v\left(\mathrm{~cm}^{-1}\right) 3060,3020,2900,1480,1475,1460,1170,1030,760$, $755,745,720 ;{ }^{1} \mathrm{H}$ NMR $\left(500 \mathrm{MHz}, \mathrm{CDCl}_{3},{ }^{1} \mathrm{H}-{ }^{1} \mathrm{H}\right.$ COSY) $\delta 5.23[\mathrm{~s}$ $4 \mathrm{H}, 5(8,11,14)-\mathrm{H}], 6.99\left[\mathrm{~m}_{\mathrm{c}}, 8 \mathrm{H}, 4^{\prime}\left(5^{\prime}\right)-\mathrm{H}\right], 7.10\left[\mathrm{~m}_{\mathrm{c}}, 4 \mathrm{H}, 4^{\prime \prime}\left(5^{\prime \prime}\right)-\mathrm{H}\right]$, $7.31-7.36\left[\mathrm{~m}, 8 \mathrm{H}, 6^{\prime}\left(3^{\prime \prime}, 6^{\prime \prime}\right)-\mathrm{H}\right], 7.38\left(\mathrm{~m}_{\mathrm{c}}, 4 \mathrm{H}, 3^{\prime}-\mathrm{H}\right) ;{ }^{13} \mathrm{C}$ NMR $(125.7$ $\mathrm{MHz}, \mathrm{CDCl}_{3}$, DEPT and $\mathrm{C}-\mathrm{H}$ correlation) $\delta 57.0[+, \mathrm{C}-5(8,11,14)]$, $66.0\left[\mathrm{C}_{\mathrm{q}}, \mathrm{C}-1(2)\right], 74.8\left[\mathrm{C}_{\mathrm{q}}, \mathrm{C}-9(10)\right], 124.3\left(+, \mathrm{C}-6^{\prime}\right), 124.4\left[+, \mathrm{C}-3^{\prime \prime}-\right.$ $\left.\left(6^{\prime \prime}\right)\right], 125.6\left(+, \mathrm{C}-3^{\prime}\right), 127.3\left(+, \mathrm{C}-4^{\prime}\right), 127.4\left(+, \mathrm{C}-5^{\prime}\right), 127.5[+$, $\left.\mathrm{C}-4^{\prime \prime}\left(5^{\prime \prime}\right)\right], 144.3\left[\mathrm{C}_{\mathrm{q}}, \mathrm{C}-4(15,18,20)\right], 145.4\left[\mathrm{C}_{\mathrm{q}}, \mathrm{C}-3(16,17,19)\right], 148.8$ $\left[\mathrm{C}_{\mathrm{q}}, \mathrm{C}-6(7,12,13)\right]$; MS (EI, $\left.70 \mathrm{eV}\right) \mathrm{m} / \mathrm{z}$ (relative intensity) $=557(17)$, $556\left(42, \mathrm{M}^{+}\right), 278(38), 153(58), 71$ (100). Anal. Calcd for $\mathrm{C}_{44} \mathrm{H}_{28}{ }^{\circ}$ 2THF $\left(\mathrm{C}_{8} \mathrm{H}_{16} \mathrm{O}_{2}\right)$ : C, 89.10; $\mathrm{H}, 6.28 ; \mathrm{O}, 4.57$. Found: $\mathrm{C}, 88.93 ; \mathrm{H}$, 6.40 .

3:4,8:9,11:12,13:14,15:16-Pentabenzopentacyclo[5.5.2.2. $\left.2^{25} \cdot 0^{1,6} \cdot 0^{6,10}\right]-$ hexadeca-3,8,11,13,15-pentaene (23) [Anthracene Adduct]. A mixture of 4,7-dihydrotribenzacepentalene dimer $(22 ; 56 \mathrm{mg}, 0.10 \mathrm{mmol})$ and anthracene $(89 \mathrm{mg}, 0.50 \mathrm{mmol})$ was stirred in a Schlenk flask under an argon atmosphere and heated to $220^{\circ} \mathrm{C}$. After $3 \mathrm{~h}$ at $220^{\circ} \mathrm{C}$ the molten dark mixture was cooled to ambient temperature. Then the main part of anthracene was sublimed off to a cooling finger and the residue purified by column chromatography (hexane/ethyl acetate, $10: 1)$ to yield $38 \mathrm{mg}(42 \%)$ of the adduct 23 as a colorless solid, mp $287^{\circ} \mathrm{C}$. Single crystals for X-ray structure analysis were obtained by recrystallization from THF/hexane: IR $(\mathrm{KBr}) v\left(\mathrm{~cm}^{-1}\right) 3065,3020$, $2925,2820,1600,1480,1470,1455,1115,1025,795,765,740,675$, 600; ${ }^{1} \mathrm{H}$ NMR (250 MHz, $\left.\mathrm{CDCl}_{3}\right) \delta 4.43(\mathrm{~s}, 2 \mathrm{H}), 4.49$ (s, $\left.1 \mathrm{H}\right), 4.88$ $(\mathrm{s}, 1 \mathrm{H}), 6.85-7.06(\mathrm{~m}, 7 \mathrm{H}), 7.07-7.24(\mathrm{~m}, 6 \mathrm{H}), 7.27-7.33(\mathrm{~m}, 2$ $\mathrm{H}), 7.35-7.46(\mathrm{~m}, 3 \mathrm{H}), 7.48-7.58(\mathrm{~d}, J=7.5 \mathrm{~Hz}, 2 \mathrm{H}) ;{ }^{13} \mathrm{C}$ NMR $\left(75.5 \mathrm{MHz}, \mathrm{CDCl}_{3}\right.$, DEPT) $\delta 53.5(+), 54.8(+), 59.2(+), 71.3\left(\mathrm{C}_{\mathrm{q}}\right)$ $73.4\left(\mathrm{C}_{q}\right), 122.7(+), 124.0(+), 124.4(+), 125.0(+), 125.1(+), 125.4$ $(+), 125.9(+), 127.2(+), 127.3(+), 127.5(+), 140.5\left(\mathrm{C}_{\mathrm{q}}\right), 142.3$ $\left(\mathrm{C}_{\mathrm{q}}\right), 145.1\left(\mathrm{C}_{\mathrm{q}}\right), 146.4\left(\mathrm{C}_{\mathrm{q}}\right), 147.0\left(\mathrm{C}_{\mathrm{q}}\right)$; MS (EI, $\left.70 \mathrm{eV}\right) \mathrm{m} / \mathrm{z}$ (relative intensity) $=456\left(20, \mathrm{M}^{+}\right), 278\left(54,[\mathrm{M}-\text { anthracene }]^{+}\right), 270(26)$, 178 (100); correct HRMS for $\mathrm{C}_{36} \mathrm{H}_{24}$, calcd 456.1878 .

2:3,5:6,13:14-Tribenzo-9,10,11,12-tetraphenyltetracyclo[5.5.2.0 $\left.0^{1,8} .0^{4,8}\right]$ tetradeca-2,5,9,11,13-pentaene (24) [Tetraphenylcyclopentadienone Adduct]. A mixture of 4,7-dihydrotribenzacepentalene dimer (22; 56 $\mathrm{mg}, 0.10 \mathrm{mmol}$ ) and tetraphenylcyclopentadienone (192 $\mathrm{mg}, 0.50 \mathrm{mmol})$ was stirred in a Schlenk flask under an argon atmosphere and heated to $220^{\circ} \mathrm{C}$. After $3 \mathrm{~h}$ at $220^{\circ} \mathrm{C}$ the melted dark mixture was cooled to ambient temperature. The reaction mixture was purified by column chromatography (hexane/benzene, $1: 1$ ) to yield $72 \mathrm{mg}$ (57\%) of the adduct 24 as a colorless solid: $\mathrm{mp} 273^{\circ} \mathrm{C}$; IR $(\mathrm{KBr}) v\left(\mathrm{~cm}^{-1}\right) 3055$, $3025,2920,1595,1575,1490,1480,1440,1070,1025,775,745,715$, $700,680,610 ;{ }^{1} \mathrm{H}$ NMR $\left(250 \mathrm{MHz}, \mathrm{CDCl}_{3}\right) \delta 5.54(\mathrm{~s}, 2 \mathrm{H}), 6.53-$ $6.75(\mathrm{~m}, 10 \mathrm{H}), 6.78-6.94(\mathrm{~m}, 3 \mathrm{H}), 6.96-7.05(\mathrm{~m}, 8 \mathrm{H}), 7.06-7.22$ $(\mathrm{m}, 7 \mathrm{H}), 7.25-7.33(\mathrm{~m}, 2 \mathrm{H}), 7.48(\mathrm{~d}, J=7.5 \mathrm{~Hz}, 2 \mathrm{H}) ;{ }^{13} \mathrm{C}$ NMR $\left(62.9 \mathrm{MHz}, \mathrm{CDCl}_{3}, \mathrm{DEPT}\right) \delta 64.6(+), 66.5\left(\mathrm{C}_{q}\right), 68.7\left(\mathrm{C}_{q}\right), 123.2$ $(+), 123.7(+), 124.5(+), 124.8(+), 126.0(+), 126.2(+), 126.3$ $(+), 126.9(+), 127.0(+), 127.3(+), 127.4(+), 128.3(+), 130.6$ $(+), 130.9(+), 131.0(+), 133.6\left(\mathrm{C}_{q}\right), 134.2(+), 135.0\left(\mathrm{C}_{\mathrm{q}}\right), 136.5$ $\left(\mathrm{C}_{q}\right), 138.8\left(\mathrm{C}_{q}\right), 139.2\left(\mathrm{C}_{\mathrm{q}}\right), 139.5\left(\mathrm{C}_{\mathrm{q}}\right), 140.3\left(\mathrm{C}_{\mathrm{q}}\right), 140.8\left(\mathrm{C}_{\mathrm{q}}\right), 142.8$ $\left(\mathrm{C}_{\mathrm{q}}\right), 145.0\left(\mathrm{C}_{\mathrm{q}}\right), 148.7\left(\mathrm{C}_{\mathrm{q}}\right)$; $\mathrm{MS}(\mathrm{EI}, 70 \mathrm{eV}) \mathrm{m} / \mathrm{z}$ (relative intensity) $=$ $634\left(100, \mathrm{M}^{+}\right), 557(10), 543(62), 480(5), 475(4), 455(8), 378(9)$, 364 (7), 278 (8); correct HRMS for $\mathrm{C}_{50} \mathrm{H}_{34}$, calcd 634.2660 .

3:4,8:9,11:12,13:14-Tetrabenzo-15-oxa-2,5-diphenylpentacyclo[5.5.2.1 $\left.{ }^{2,5} .0^{1,6} .0^{6,10}\right]$ pentadeca-3,8,11,13-tetraene (25) [Diphenylisobenzofuran Adduct]. To a solution of diphenylisobenzofuran $(135 \mathrm{mg}$, $0.50 \mathrm{mmol}$ ) in $10 \mathrm{~mL}$ of THF was added at $-78{ }^{\circ} \mathrm{C}$ a suspension of dipotassium tribenzacepentalenediide $\left(\mathbf{5}-\mathrm{K}_{\mathbf{2}} ; 40 \mathrm{mg}, 0.10 \mathrm{mmol}\right)^{49}$ in 2 $\mathrm{mL}$ of $n$-hexane. Then a solution of water $(90 \mu \mathrm{L}, 0.50 \mathrm{mmol})$ in 10 $\mathrm{mL}$ of THF was injected via a syringe pump overnight. The reaction mixture was allowed to warm slowly to ambient temperature. After addition of $50 \mathrm{~mL}$ of ether, the yellow mixture was extracted twice with brine $(20 \mathrm{~mL}$ each). The organic layer was separated, dried over $\mathrm{MgSO}_{4}$, and concentrated in vacuo. Then the crude product was purified by column chromatography (hexane/ethyl acetate, 10:1) to yield
$15 \mathrm{mg}(27 \%)$ of 25 as a colorless solid: $\mathrm{mp} 299^{\circ} \mathrm{C}$; IR $(\mathrm{KBr}) v\left(\mathrm{~cm}^{-1}\right)$ $3080,3030,2860,1590,1445,1430,1425,990,750,740,695,610$; ${ }^{1} \mathrm{H}$ NMR $\left(250 \mathrm{MHz}, \mathrm{CDCl}_{3}\right) \delta 4.67(\mathrm{~s}, 1 \mathrm{H}), 4.78(\mathrm{~s}, 1 \mathrm{H}), 6.32(\mathrm{~d}, J$ $=7.5 \mathrm{~Hz}, 1 \mathrm{H}), 6.76(\mathrm{t}, J=7.5 \mathrm{~Hz}, 1 \mathrm{H}), 6.91-7.23(\mathrm{~m}, 9 \mathrm{H}), 7.28-$ $7.66(\mathrm{~m}, 13 \mathrm{H}), 7.92(\mathrm{~d}, J=7.0 \mathrm{~Hz}, 2 \mathrm{H}) ;{ }^{13} \mathrm{C} \mathrm{NMR}\left(62.9 \mathrm{MHz}, \mathrm{CDCl}_{3}\right.$, DEPT) $\delta 57.0(+), 78.6\left(\mathrm{C}_{\mathrm{q}}\right), 83.2\left(\mathrm{C}_{\mathrm{q}}\right), 92.7\left(\mathrm{C}_{\mathrm{q}}\right), 93.0\left(\mathrm{C}_{\mathrm{q}}\right), 120.5$ $(+), 120.8(+), 123.4(+), 124.2(+), 124.3(+), 124.4(+), 124.8$ $(t), 125.9(+), 126.1(+), 126.2(+), 126.3(+), 126.5(t), 127.2$ $(+), 127.3(+), 127.4(+), 127.5(+), 127.6(+), 127.7(+), 128.1$ $(+), 128.7(+), 137.7\left(\mathrm{C}_{q}\right), 137.8\left(\mathrm{C}_{\mathrm{q}}\right), 143.1\left(\mathrm{C}_{\mathrm{q}}\right), 144.3\left(\mathrm{C}_{\mathrm{q}}\right), 144.6$ $\left(\mathrm{C}_{\mathrm{q}}\right), 145.4\left(\mathrm{C}_{\mathrm{q}}\right), 145.7\left(\mathrm{C}_{\mathrm{q}}\right), 146.3\left(\mathrm{C}_{\mathrm{q}}\right), 147.9\left(\mathrm{C}_{\mathrm{q}}\right), 148.5\left(\mathrm{C}_{\mathrm{q}}\right)$; MS $(\mathrm{EI}, 70 \mathrm{eV}) \mathrm{m} / \mathrm{z}$ (relative intensity) $=549(3), 548\left(7, \mathrm{M}^{+}\right), 451(15)$, 278 (9), 270 (100), 257 (19), 241 (8), 201 (43); correct HRMS for $\mathrm{C}_{42} \mathrm{H}_{28} \mathrm{O}$, calcd 548.2140 .

X-ray Measurements of $\mathbf{5}-\mathbf{L i}_{2}$ and 23. All data were collected at low temperature using an oil-coated shock-cooled crystal ${ }^{34}$ on a StoeSiemens AED with Mo $\mathrm{K} \alpha(\lambda=71.073 \mathrm{pm})$ radiation. The structures were solved by direct methods using SHELXS- $90^{46}$ and refined with all data on $F^{2}$ with a weighting scheme of $w^{-1}=\sigma^{2}\left(F_{0}^{2}\right)+(g 1 \cdot P)^{2}+$ $g 2 \cdot P$ with $P=\left(F_{0}{ }^{2}+2 F_{\mathrm{c}}{ }^{2}\right) / 3$ using SHELXL-93. ${ }^{47}$ The hydrogen atom positions were refined with a riding model. Further details of the crystal structure investigations are available on request from the Director of the Cambridge Crystallographic Data Center, University Chemical Laboratory, Lensfield Road, GB-Cambridge CB2 1EW, U.K., by quoting the full journal citation.

Crystal Data for 5- $\mathrm{Li}_{2}: \mathrm{C}_{46} \mathrm{H}_{72} \mathrm{Li}_{2} \mathrm{O}_{12}, M=830.92$, orthorhombic, space group $P 2{ }_{1} 2_{\mathrm{f}}{ }_{\mathrm{l}}, a=1301.58(14), b=1842.2(2), c=1993.0(2)$ pm, $V=4.7788(9) \mathrm{nm}^{3}, Z=4, D_{\mathrm{c}}=1.155 \mathrm{Mg} \mathrm{m}^{-3}, F(000)=1800$, $T=153 \mathrm{~K}, \mu($ Mo $\mathrm{K} \alpha)=0.081 \mathrm{~mm}^{-1}$. Data were collected by the $2 \theta / \omega$ method in the range of $4^{\circ}<2 \theta<50^{\circ}$. Of a total of 9339 reflections, 4670 were independent; the largest difference peak and hole were 249 and $-318 \mathrm{e} \mathrm{m}^{-3}, R 1=0.048(I>2 \sigma(I))$ and $w R 2=0.1483$ (all data). The disordered dimethoxyethane molecules were refined by using similarity restraints. Unfortunately, the absolute structure could not be established unequivocally.

Crystal Data for 23: $\mathrm{C}_{42} \mathrm{H}_{36} \mathrm{O}_{1.5}, M=564.71$, monoclinic, space group $P 2 \mathrm{~J} / c, a=951.2(3), b=1289.9(5), c=2464(2) \mathrm{pm}, V=$ $3.009(2) \mathrm{nm}^{3}, Z=4, D_{\mathrm{c}}=1.247 \mathrm{Mg} \mathrm{m}^{-3}, F(000)=1200, T=153$ $\mathrm{K}, \mu(\mathrm{Mo} \mathrm{K} \alpha)=0.074 \mathrm{~mm}^{-1}$. Data were collected by the $2 \theta / \omega$ method in the range of $7^{\circ}<2 \theta<45^{\circ}$. Of a total of 6374 reflections, 3919 were independent; the largest difference peak and hole were 336 and $-302 \mathrm{e} \mathrm{m}^{-3}, R 1=0.060(I>2 \sigma(I))$ and $w R 2=0.1654$ (all data). The disorder of the tetrahydrofuran was refined by using similarity restraints.

Acknowledgment. This work was supported by the Deutsche Forschungsgemeinschaft, the Fonds der Chemischen Industrie, the Nolkswagenstiftung and through a collaborative research grant by the NATO Scientific Affairs Division. R.H. and B.O. are indebted to the Fonds der Chemischen Industrie for Ph.D. grants. We are grateful to the companies BASF, Bayer, Hoechst, Degussa AG, and Hüls AG for generous gifts of chemicals.

Supporting Information Available: Tables giving crystal data and structure refinement, atomic coordinates, equivalent isotropic displacement parameters, bond lengths and angles, anisotropic displacement parameters, and hydrogen coordinates for figures showing ORTEP diagrams (17 pages). This material is contained in many libraries on microfiche, immediately follows this article in the microfilm version of the journal, can be ordered from the ACS, and can be downloaded from the Internet; see any current masthead page for ordering information and Internet access instructions.

JA952172F 